\title{
II. Regionale Profile des Nationalsozialismus vor 1933
}




\section{Hellmuth Auerbach}

\section{Regionale Wurzeln und Differenzen der NSDAP 1919-1923}

Die NSDAP ist bekanntlich in München entstanden, aber sie war in ihren Anfängen keine rein Münchner Erscheinung. In den Jahren bis 1923 entwickelte sie in Bayern und außerhalb regionale Schwerpunkte und Besonderheiten. Es war auch keineswegs so, daß Adolf Hitler als „Führer“ von Anfang an diktatorisch den Weg der Partei bestimmte. Gerade in Bayern mußte er sich erst durchsetzen und die Konkurrenz anderer völkischer Propagandisten in und außerhalb der Partei abwehren. Der folgende Beitrag soll vor allem diese Entwicklung und die regionalen Differenzen in der Frühzeit der Partei aufzeigen.

\section{Die Vorläuferorganisationen}

München war schon während des Ersten Weltkriegs ein Hauptagitationszentrum der sich im Kampf gegen die Politik Bethmann Hollwegs und seiner Nachfolger ständig steigernden nationalistischen und alldeutschen Bewegung geworden. Im Verein damit wurde es dies sehr bald auch für den völkischen Antisemitismus. Im Juli 1916 entstand in München ein „Volksausschuß für die rasche Niederkämpfung Englands“, dem eine Reihe einflußreicher Adeliger und Universitätsprofessoren angehörte. Fast die gleichen Leute gaben in dem ein gutes Jahr später entstehenden bayerischen Landesverband der Deutschen Vaterlandspartei den Ton $a^{1}$. Ein gesellschaftlicher und geistiger Mittelpunkt dieser Kreise wurde das Haus des Verlegers Julius F. Lehmann, der ab 1917 die alldeutsch-völkische Zeitschrift „Deutschlands Erneuerung“ herausbrachte, zu deren Herausgebern u.a. der Vorsitzende des Alldeutschen Verbandes, Justizrat Heinrich Claß, und der Rassentheoretiker Houston Stewart Chamberlain gehörten. Auch der 1912 auf Initiative von Theodor Fritsch entstandene völkische Geheimbund „Germanen-Orden“ war in München aktiv; am 1. November 1918 soll er allein in München ca. 200 Mitglieder gehabt haben, in ganz Bayern waren es ca. $1500^{2}$. Da der Germanen-Orden nicht an die Öffentlichkeit treten wollte, gründeten einige seiner Mitglieder Ende 1917 einen Verein namens „Thule-Gesellschaft“, der bald die ganze Prominenz der Völkischen in München zu seinen Mitgliedern zählte ${ }^{3}$. Es war ein ausgesprochen großbürgerlicher Verein mit starkem studentischen Ein-

${ }^{1}$ Zum Volksausschuß und zum bayerischen Landesverband der Deutschen Vaterlandspartei vgl. Willy Albrecht, Landtag und Regierung in Bayern am Vorabend der Revolution von 1918. Studien zur gesellschaftlichen und staatlichen Entwicklung Deutschlands von 1912-1918, Berlin 1968, S. $164 \mathrm{f}$. u. S. $286 \mathrm{f}$.

${ }^{2}$ Zum Germanenorden vgl. Uwe Lohalm, Völkischer Radikalismus. Die Geschichte des Deutschvölkischen Schutz- und Trutz-Bundes 1919-1923, Hamburg 1970, S.61 ff.

${ }^{3}$ Dazu vor allem Reginald H. Phelps, „Before Hitler came“. Thule Society and Germanen Orden, in: Journal of Modern History (JMH) 35 (1963), S.245-261; Hermann Gilbhard, Die Thule-Gesellschaft - Vom okkulten Mummenschanz zum Hakenkreuz, München 1994. 
schlag, streng antisemitisch auf der völkischen Ideologie aufbauend, man dekorierte mit Hakenkreuzen, trieb Runenkunde und schwärmte für die Germanen, wie man sie sich in solchen Kreisen vorstellte. Natürlich glaubte man auch an die Idee einer ${ }_{n}$ jüdischen Weltverschwörung “ und fand an Gottfried Feders Theorie von der „Brechung der Zinsknechtschaft" Gefallen ${ }^{4}$. Feder war Mitglied der Thule-Gesellschaft, ebenso Dietrich Eckart, Alfred Rosenberg und andere, die man später in der NSDAP wiederfindet.

Vorsitzender der auf München beschränkten Thule-Gesellschaft war ein Freiherr von Sebottendorff $^{5}$ - von obskurer, ursprünglich bürgerlicher Herkunft, aber offensichtlich vermögend. Er mietete in einem Seitenteil des Hotels „Vier Jahreszeiten“ einige Räume an, die bald auch von anderen völkisch-antisemitisch gesinnten Gruppierungen in München benutzt wurden, vor allem in der Revolutions- und Rätezeit, als es für rechtsgerichtete Organisationen ratsam schien, im Hintergrund zu bleiben. Die Thule-Gesellschaft betätigte sich während dieser Zeit konspirativ im gegenrevolutionären Sinne, versuchte eine antimarxistische Bürgerwehr mit aufzubauen und vermittelte Freiwillige in entstehende Freikorps. Einige Mitglieder haben Waffenlager angelegt und zu Sabotagezwecken Ausweise und andere Papiere der KPD und der Roten Armee entwendet und gefälscht. Sebottendorff verließ München am 16. April 1919. Bei einer kurz danach von den Roten durchgeführten Durchsuchung der Räume der Thule-Gesellschaft wurden u. a. Mitgliederlisten gefunden, die zu einer Verhaftungsaktion führten. Ihr fielen aber vor allem solche Leute zum Opfer, die an der Konspiration nicht beteiligt waren. Sieben von ihnen wurden bei dem berüchtigten sogenannten "Geiselmord“ am 30. April 1919 im Luitpoldgymnasium in München erschossen ${ }^{6}$.

Die propagandistische Ausnützung dieses "Geiselmordes" durch die „Weißen" und das rechtsgerichtete Bürgertum in München steigerte noch die Rache-Stimmung und die antisemitische Haltung in der bürgerlichen Bevölkerung und unter den Soldaten. Man sah die Münchner Revolution und ihre Folgen als ein Werk der Juden und Bolschewisten an. Diese Stimmung setzte sich fort in den Wehrverbänden und nationalen Vereinen und prägte im Verein mit der Gegnerschaft gegen das "rote“ Berlin stark das politische Klima in München und Oberbayern in den frühen 20er Jahren. Davon profitierten natürlich auch die Nationalsozialisten und ihre Vorgänger. Die Niederschlagung der Revolution bereitete also den Rechtsradikalen den Boden.

Sebottendorff konnte im Juni 1918 nach dem Tode des Verlegers Franz Eher dessen Lokalblatt "Münchener Beobachter" erwerben, das bald mit dem Untertitel "Unabhängige Zeitung für deutsche und völkische Politik" erschien. Nach dem Ende der Revolution firmierte es offen auch als „Ankündigungsblatt nationaler Vereine“. Der Verlag des „Münchener Beobachters" befand sich anfangs in der Thierschstraße, dann in der SchellingstraBe und wurde von Hans Georg Grassinger ${ }^{8}$ geleitet, einem Mitglied der Deutschsozialisti-

${ }^{4}$ Albrecht Tyrell, Gottfried Feder and the NSDAP, in Peter D. Stachura ( $\left.\mathrm{Hg}.\right)$, The Shaping of the Nazi State, London 1978, S.48-87.

${ }^{5}$ Ellic Howe, Rudolph Freiherr von Sebottendorff, hg. v. Albrecht Götz von Olenhusen, Freiburg i. Br. 1989 (unveröffentlichtes Manuskript im Institut für Zeitgeschichte, künftig IfZ); Rudolf von Sebottendorff, Bevor Hitler kam. Urkundliches aus der Frühzeit der nationalsozialistischen Bewegung, 2. Aufl. München 1934.

${ }^{6}$ Dazu insbes. Heinrich Hillmayr, Roter und Weißer Terror in Bayern nach 1918. Ursachen, Erscheinungsformen und Folgen der Gewalttätigkeiten im Verlauf der revolutionären Ereignisse nach dem Ende des Ersten Weltkrieges, München 1974, S.100ff.

${ }^{7}$ Adolf Dresler, Der „Münchener Beobachter“ 1887-1918, Würzburg 1940.

${ }^{8}$ IfZ ZS 50, Zeugenschrifttum Georg Grassinger. 
chen Partei. Ab 1.Januar 1920 erschien das Blatt unter dem Namen „Völkischer Beobachter" (VB)?.

Einer der Mitarbeiter des „Münchener Beobachters“ war der Journalist Karl Harrer, wie Grassinger ebenfalls Mitglied der Thule-Gesellschaft und von dieser beauftragt, gleichgesinnte, also national eingestellte Leute in der Arbeiterschaft zu finden. Harrer stieß am 2. Oktober 1918 auf den Werkzeugschlosser Anton Drexler, ein Mitglied der Deutschen Vaterlandspartei, der im März 1917 einen „Freien Arbeiterausschuß für einen guten Frieden" gegründet hatte und an diesem Tag erstmals mit einer öffentlichen Versammlung um Mitglieder warb. Drexler verstand sich als nationaler Sozialist ${ }^{10}$. Harrer gewann ihn für einen „politischen Arbeiterzirkel“ innerhalb der Thule-Gesellschaft. Drexler wollte aber öffentlich wirken und gründete am 5.Januar 1919 eine „Deutsche Arbeiterpartei“ (DAP), deren Vorsitz er übernahm. Harrer behielt jedoch großen Einfluß auf die neue Partei und sorgte für deren Unterstützung durch die Thule-Gesellschaft.

Die Anhänger Drexlers, großenteils Handarbeiter der Münchner Eisenbahnwerkstätten, betrachteten sich als Handwerker und nicht als Proletarier. Zum Selbstverständnis der Arbeiter, die die neue Partei ansprechen wollte, heißt es in deren Richtlinien: „Die DAP will die Adelung des deutschen Arbeiters. Die gelernten und ansässigen Arbeiter haben ein Recht, zu dem Mittelstand gerechnet zu werden. Zwischen Arbeiter und Proletarier soll ein scharfer Trennungsstrich gezogen werden ... " ${ }^{11}$ In seiner Bekenntnisschrift „Mein politisches Erwachen“ schreibt Drexler: „In der neuen kommenden Weltordnung muß ein neues geeinigtes Deutschland erstehen. Parteienhader, Klassenkampf und Bruderhaß müssen einem festen Nationalismus weichen. Aus den politischen Obdacblosen, die zu Hunderttausenden unter den Beamten, Kleinbürgern und Arbeitern aus Unzufriedenheit mit ihren alten Parteien entstanden sind, soll ein neuer, nationaler Bürgerbund' (oder wie man es sonst nennen will) entstehen. ${ }^{12}$ „Der Jude“ wird von Drexler als „Verräter an der Arbeiterschaft" gesehen; der jüdische Bolschewismus wolle auch die Ausrottung des Mittelstands. Die Sozialdemokratie sei „die Kampftruppe des Judentums“. Die Mitglieder der DAP und dann der NSDAP waren weniger Arbeiter als vielmehr Kleinbürger, die am Stammtisch ihren nationalen Sehnsüchten nachhingen. Dazu kamen völkisch gesinnte Studenten, die die Thule-Gesellschaft und der Deutschvölkische Schutz- und Trutz-Bund auf die neue nationale Partei aufmerksam machten. Viele dieser Leute traten ihr bei. Um die Jahreswende 1919/20 hatte die DAP etwas über 200 Mitglieder.

Der Deutschvölkische Schutz- und Trutz-Bund war im Frühjahr 1919 aus dem Alldeutschen Verband hervorgegangen. Geistige Grundlage seiner Tätigkeit war vor allem die Schrift des Verbandsvorsitzenden des ADV, Justizrat Heinrich Claß, die 1912 unter dem

9 Vgl. Sonja Noller, Die Geschichte des „Völkischen Beobachters“ von 1920-1923, Diss. phil., München 1956; Roland V.Layton jr., The Voelkischer Beobachter, 1925-1933. A Study of the Nazi Party Newspaper in the Kampfzeit, Diss. phil., Univ. of Virginia 1965; Roland V.Layton jr., The Völkischer Beobachter, 1920-1933: The Nazi Party Newspaper in the Weimar Era, in: Central European History (CEH) 3 (1970), S. 353-382.

${ }^{10} \mathrm{Zu}$ Drexler: Reginald H.Phelps, Anton Drexler - Der Gründer der NSDAP, in: Deutsche Rundschau 87 (1961), S. 1134-1143; Max H. Kele, Nazis and Workers. National Socialist Appeals to German Labor, 1919-1933, Chapel Hill N.C. 1972, S. 31 ff.; Anton Joachimsthaler, Die Anfänge der NSDAP, in: München - „Hauptstadt der Bewegung “

${ }^{11}$ Die Richtlinien vom 5.Januar 1919 zit. n. Georg Franz-Willing, Ursprung der Hitlerbewegung 1919-1922, Preußisch Oldendorf 1974, S. 114.

${ }^{12}$ Anton Drexler, Mein politisches Erwachen. Aus dem Tagebuch eines deutschen sozialistischen Arbeiters, München 1919, S. 25 (Hervorhebung im Original). 
Titel „Wenn ich der Kaiser wär" erschienen war ${ }^{13}$. Der über ganz Deutschland verbreitete Schutz- und Trutz-Bund war der Versuch einer übergreifenden Formierung der völkischantisemitischen Bewegung, eine Arbeitsgemeinschaft aller völkischen Verbände mit lockerem Zusammenhalt. Er wuchs dank der Mitarbeit vieler Verbände schnell an: Ende 1919 hatte er schon annähernd 30000 Mitglieder, bis Oktober 1920 über 100000 . Bis zu seiner Auflösung im Sommer 1922 erreichte der Bund eine Gesamtzahl von ca. 200000 Mitgliedern; sie waren aufgegliedert in Ortsgruppen, die Gesamtheit der Ortsgruppen eines Landes war zu einem Gau zusammengefaßt.

In München bildete sich im Sommer 1919 eine Ortsgruppe unter der Leitung des Stadtschulrats a.D. Wilhelm Rohmeder, der zugleich Vorsitzender des Deutschen Schulvereins war. Fast die ganze Thule-Gesellschaft trat auch dem Schutz- und Trutz-Bund bei, der ihre Räume im Hotel „Vier Jahreszeiten“ mitbenutzte. Eine Doppelmitgliedschaft in verschiedenen nationalen und antisemitischen Vereinigungen war damals nicht nur in München gang und gäbe. Im Juli 1920 war der Schutz- und Trutz-Bund mit fast 40000 Mitgliedern die stärkste Organisation der völkischen Bewegung in München ${ }^{14}$. Auch Hitler anerkannte später, daß der Bund der "große Vorkämpfer in der Judenfrage“ war.

\section{Hitlers Anfänge}

Es ist hier nicht der Ort, noch einmal zu berichten, wie Hitler am 12.September 1919 als V-Mann eines Aufklärungskommandos der Reichswehr zur DAP stieß, sich von Drexler anwerben ließ und für die Partei als „Werbeobmann“ fungierte ${ }^{15}$. Nach seinem Eintritt brachte Hitler neue Leute in die Partei. In der jungen DAP bildeten sich bald zwei Gruppen: die Drexler-Harrer-Gruppe (Arbeiter, Handwerker und kleine Geschäftsleute) und die Hitler-Gruppe (größtenteils ehemalige Frontsoldaten, die nichts mit den bürgerlichen Lebensidealen zu tun hatten). Beide Gruppen waren völkisch-nationalistisch orientiert. Drexler stand zwischen Harrer und Hitler, tendierte aber zu letzterem. Die Frage, ob die DAP eine Loge - ähnlich der Thule-Gesellschaft, wie Harrer es wollte - oder eine Massenbewegung sein sollte, wurde im Sinne Hitlers gelöst. Harrer zog sich Anfang 1920 von der Partei zurück, im Zusammenhang mit der Führungskrise im Sommer 1921 wurde er ganz ausgeschlossen.

Da Hitler bei der Reichswehr, aus der er am 3. März 1920 ausschied, und auch sonst nichts zu tun hatte, konnte er für die kleine Partei viel Zeit und Energie einsetzen und seine Position dort ausbauen. Nachdem er am 7.Januar 1920 eine große, erfolgreiche antisemitische Massenveranstaltung des Deutschvölkischen Schutz- und Trutz-Bundes miterlebt hatte, setzte er es trotz großer Bedenken seiner Parteifreunde durch, daß die DAP eine ähnliche Massenversammlung einberief. Sie fand am 24. Februar 1920 im Festsaal des

${ }^{13}$ Vgl. dazu Lohalm, Völkischer Radikalismus, S.20; Hellmuth Auerbach, Nationalsozialismus vor Hitler, in: Wolfgang Benz, Hans Buchheim, Hans Mommsen (Hg.), Der Nationalsozialismus. Studien zur Ideologie und Herrschaft, Frankfurt/M. 1993, S. $22 \mathrm{ff}$.

${ }^{14}$ Lohalm, Völkischer Radikalismus, S. 293.

${ }^{15}$ Vgl. Hellmuth Auerbach, Hitlers politische Lehrjahre und die Münchener Gesellschaft 1919-1923. Versuch einer Bilanz anhand der neueren Forschung, in: Vierteljahrshefte für Zeitgeschichte (VfZ) 25 (1977), S. 1-45; Reginald H. Phelps, Hitler and the Deutsche Arbeiterpartei, in: American Historical Review 68 (1963), S. 974-986; Anton Joachimsthaler, Hitlers Eintritt in die Politik und die Anfänge der NSDAP, in: München - „Hauptstadt der Bewegung“, S.71-82; Gilbhard, Thule-Gesellschaft, S. $149 \mathrm{ff}$. 
Hofbräuhauses statt und soll von etwa 2000 Leuten besucht worden sein, darunter aber viele Gegner. Hauptredner des Abends war der durch sein Auftreten im Schutz- und Trutz-Bund und durch seine Schriften bekannte Mittelstandspolitiker Dr. Johannes Dingfelder. Nach ihm gab Hitler das neue Programm der Partei bekannt, die sich nun „Nationalsozialistische Deutsche Arbeiterpartei“ (NSDAP) nannte ${ }^{16}$. Die 25 Programmpunkte sind von Drexler entworfen und von Hitler redigiert worden. Als ihre geistigen Paten müssen aber Dietrich Eckart, der nationale Dichter, und Gottfried Feder, der Propagandist der „Brechung der Zinsknechtschaft“ gelten. Die Hauptpunkte des Programms sind national kleinbürgerlich, keineswegs national sozialistisch ${ }^{17}$. Für Hitler stand das Programm ohnehin nicht im Vordergrund. Er hielt sich vor allem an die vier ersten Punkte: 1.Schaffung eines Großdeutschland, 2. Aufhebung der Friedensverträge von Versailles und Saint-Germain, 3. Schaffung von „Lebensraum“ für das deutsche Volk, 4. Kampf gegen die „jüdische Rasse“. Im „Völkischen Beobachter" vom 28. Februar 1920 wurde kurz über die Versammlung der DAP vom 24. des Monats und ihre Umwandlung in die NSDAP berichtet. Über das Programm der neuen NSDAP heißt es, daß dieses „in den Grundzügen dem Programm der Deutsch-sozialistischen Partei nahe kommt" ${ }^{* 18}$.

Der „Völkische Beobachter “ erschien ab 1. April 1920 dreimal wöchentlich. Zu seiner Unterstützung wurde am 28.Juli 1920 ein „Bund der Beobachterfreunde“ gegründet, an dessen Gründungsversammlung auch Hitler teilnahm ${ }^{19}$. Die NSDAP war sehr an einer Zeitung interessiert. Als der „Beobachter“ Ende des Jahres 1920 in finanzielle Schwierigkeiten geriet und zum Verkauf stand, griff Hitler deshalb zu. Durch Vermittlung von Dietrich Eckart und dem Augsburger Fabrikanten Dr. Gottfried Grandel konnte er das nötige Geld aufbringen, um die Zeitung am 17. Dezember für die NSDAP zu erwerben. 60000 Mark hat Oberst Ritter von Epp auf Fürsprache Röhms aus einem Reichswehrfond zugeschossen. 120000 Mark Schulden wurden nur langsam von der Partei abgetragen $^{20}$. Am Inhalt des VB änderte die Übernahme durch die NSDAP vorerst gar nichts ${ }^{21}$. Als Hauptschriftleiter setzten die Nationalsozialisten Hugo Machhaus ein, der den Posten aber nur bis August 1921 behielt. Sein Nachfolger wurde bis März 1923 Dietrich Ekkart, dann Alfred Rosenberg. Erst am 8. Februar 1923 wurde der „Völkische Beobachter“ eine Tageszeitung. Die NSDAP hatte damit ein Presseorgan, mit dem sie weit über München hinaus Propaganda machen konnte und dessen Auflage rasch bis November 1923 auf ca. 25000 Exemplare anstieg 22.

Der Aufstieg der NSDAP im Laufe der Jahre 1920 und 1921 vollzog sich in bewußter Anlehnung an den Deutschvölkischen Schutz- und Trutz-Bund, viele seiner Mitglieder wurden auch Mitglieder der NSDAP. Hitler kam es in dieser Zeit vor allem darauf an, die Partei und ihre Parolen bekanntzumachen und Aufsehen zu erregen. Die NSDAP hat-

${ }^{16}$ Die DAP sollte ursprünglich in „Deutsche sozialistische Arbeiterpartei“ umbenannt werden. Um sich von der Deutsch-sozialistischen Partei abzugrenzen, setzten Drexler und Hitler den Namen NSDAP durch (ebd. S. 77).

${ }^{17}$ Das Programm im Auszug in: München - ${ }_{n}$ Hauptstadt der Bewegung ${ }^{\prime}$, S. $74 \mathrm{f}$.

${ }^{18}$ Völkischer Beobachter Nr.17 vom 28. Februar 1920, S. 3; Noller, Geschichte, S. 173.

${ }^{19}$ Vgl. ebd., S.233 f.; Albrecht Tyrell, Vom ,Trommler' zum ,Führer'. Der Wandel von Hitlers Selbstverständnis zwischen 1919 und 1924 und die Entwicklung der NSDAP, München 1975, S. $91 \mathrm{f}$.

${ }^{20}$ Zum Erwerb des VB durch die NSDAP vgl. vor allem den Exkurs ebd., S. $175 \mathrm{ff}$.

${ }^{21}$ Noller, Geschichte, S. 322.

${ }^{22}$ Charles F. Sidman, Die Auflagen-Kurve des Völkischen Beobachters und die Entwicklung des Nationalsozialismus, Dezember 1920-November 1923, in: VfZ 13 (1965), S. 112-118. 
te ein sehr dichtes Veranstaltungsprogramm, im September 1920 vier Großveranstaltungen hintereinander im Münchner Kindl-Keller, ab Februar 1921 oft im Zirkus-Krone-Bau, jeweils mit mehreren Tausenden von Zuhörern. Hitler überflügelte damit den Schutz- und Trutz-Bund. Er war der weitaus häufigste Redner bei solchen Veranstaltungen und bald bekannt als der wirkungsvollste Agitator gegen die Juden, die Alliierten, den Versailler Vertrag und gegen die ganze Berliner Reichsregierung. In einer Zeit ohne Radio und ohne Fernsehen waren die großen Massenveranstaltungen ein attraktives Spektakel; man liest immer wieder davon, daß Hitlers leidenschaftliche Reden der damaligen Zeit auf viele Leute faszinierend wirkten ${ }^{23}$. Er wurde von den völkisch-national gesinnten Kreisen dementsprechend protegiert. Auch die Partei profitierte von seiner Attraktivität. Der Parteigründer, Drexler, trat dagegen für die Öffentlichkeit ganz in den Hintergrund.

\section{Der Aufbau der NSDAP}

Dank Hitler übertraf die NSDAP die anderen völkisch-nationalistischen Gruppen ${ }^{24}$ in München zwar an Propagandawirkung, aber sie war nur eine unter vielen solchen Gruppen und bei weitem nicht die stärkste. Nach den neuesten Forschungen ${ }^{25}$ soll die NSDAP Ende 1920 ca. 2350 Mitglieder gehabt haben, Ende 1921 4300, 1922 8200; bis November 1923 sei sie auf über 55000 angestiegen, was wohl auf die zunehmende Agitation und auf die inzwischen erfolgte Auflösung der Einwohnerwehren und Freikorps zurückzuführen ist. Die stellungslos gewordene Soldateska und die revolutionär gesinnte Jugend gingen nun zur NSDAP und zur SA. Für das starke Anwachsen der Partei 1923 waren aber auch die wachsende Inflation, die verstärkten französischen Forderungen nach Reparationszahlungen und die drohende Besetzung der Ruhr verantwortlich zu machen.

Die Feststellung der sozialen Zusammensetzung ${ }^{26}$ der frühen NSDAP gestaltet sich etwas schwierig angesichts der unsicheren Quellenlage (auch hinsichtlich der Berufsangaben in den Mitgliederlisten) und des Umstands, daß sich die Sozialhistoriker nicht darüber einig sind, ob ein ausgebildeter Facharbeiter zum unteren Mittelstand gerechnet werden kann oder nicht. Man bestreitet aber nicht, daß die NSDAP von Anfang an eine Volkspartei war, in der alle Klassen repräsentiert waren. Der untere Mittelstand (Handwerker und kleine Kaufleute, Angestellte und untere Beamte) bildete die Hauptmasse der

${ }^{23}$ Vgl. Wilfried Rudloff, Auf dem Weg zum „Hitler-Putsch“: Gegenrevolutionäres Milieu und früher Nationalsozialismus in München, in: München - „Hauptstadt der Bewegung“, S.97-104, hier S.99; Auerbach, Hitlers politische Lehrjahre, S. 26.

${ }^{24}$ Zum völkisch-nationalistischen Milieu und den einzelnen Gruppen in München vor allem Hans Fenske, Konservativismus und Rechtsradikalismus in Bayern nach 1918, Bad Homburg 1969; Bruno Thoss, Der Ludendorff-Kreis 1919-1923. München als Zentrum der mitteleuropäischen Gegenrevolution zwischen Revolution und Hitler-Putsch, München 1978.

${ }^{25}$ Peter Manstein, Die Mitglieder und Wähler der NSDAP 1919-1933. Untersuchungen zu ihrer schichtmäßigen Zusammensetzung. 3. Aufl. Frankfurt/M. 1990, S.115 (nach Madden und Kater).

${ }^{26}$ Hierzu vor allem Michael H. Kater, Zur Soziographie der frühen NSDAP, in: VfZ 19 (1971), S. 124159; James Paul Madden, The Social Composition of the Nazi Party, 1919-1930, Diss. phil., University of Oklahoma 1976; Paul Madden, Some Social Characteristics of Early Nazi Party Members, 1919-23, in: CEH 15 (1982), S.34-56; Wolfgang Schieder, Die NSDAP vor 1933. Profil einer faschistischen Partei, in: Geschichte und Gesellschaft (GG) 19 (1993), S. 141-154; Jürgen W. Falter u. Michael H.Kater, Wähler und Mitglieder der NSDAP. Neue Forschungsergebnisse zur Soziographie des Nationalsozialismus 1925 bis 1933, in: GG 19 (1993), S. 155-177, dort weitere Literaturhinweise. 
Mitglieder. Die Aussage, der typische Nationalsozialist in München sei ein „Münchner Durchschnittsbürger" gewesen, dürfte allerdings für die Zeit nach 1925 eher gerechtfertigt sein $^{27}$. Aber die These vom „Extremismus der Mitte“ trifft für die frühe Zeit der NSDAP sicher in besonderem Maße $\mathrm{zu}^{28}$. Gerade in dieser Zeit überwog auch sehr stark das männliche Element. Aber unter denjenigen, die in den ersten Monaten nach der Wiedergründung der NSDAP Ende Februar 1925 in München der Partei beitraten, waren immerhin 44,6\% Frauen. Das Durchschnittsalter der Mitglieder war niedrig (27 bis 33 Jahre). Die frühe Entscheidung der DAP-Führung, jedes Leitungsgremium einer Ortsgruppe sollte aus $70 \%$ Arbeitern bestehen, wurde weitgehend unbeachtet gelassen oder war unmöglich zu erfüllen. Keine der Ortsgruppen hatte mehr als $5 \%$ Mitglieder aus der Arbeiterklasse ${ }^{29}$.

Die Münchner Ortsgruppe der NSDAP war Mitte 1921 in sieben Sektionen aufgeteilt worden: Lehel (= Innere Stadt), Haidhausen, Neuhausen, Giesing, Schlachthausviertel, Westend und Schwabing. Der Zusammenhalt innerhalb der Sektionen war gerade in den ersten Jahren oft sehr eng. Man traf sich nicht nur einmal in der Woche zu Parteiversammlungen, Sprechabenden und ähnlichem, sondern veranstaltete auch gemeinsame Feiern und Ausflüge ${ }^{30}$. Es ging eher familiär zu. Kristallisationspunkt der Sektionen und in kleineren Orten der Ortsgruppen war das Stammlokal; in der frühen NSDAP spielte wie bei den meisten anderen Vereinen der Stammtisch eine große Rolle ${ }^{31}$. Gerade dort entwickelte man ein politisches Heimatgefühl, man fühlte sich unter sich und pflegte seine Vorurteile. In dieser kleinbürgerlich geprägten völkisch-nationalistischen Gesinnungsgemeinschaft

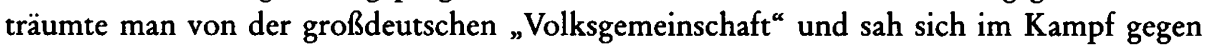
die „jüdische Weltverschwörung“, die man für alles Unglück in Deutschland verantwortlich machte. Wie Rainer Lepsius gezeigt hat, lag diesem sozialen Milieu des Mittelstands ein moralischer Geltungsanspruch zugrunde, der sich mit einem latenten, für diese Schicht spezifischen Nationalismus verband ${ }^{32}$.

\section{Die NSDAP außerbalb Münchens}

Die NSDAP beschränkte ihre Aktivität in den ersten beiden Jahren faktisch auf München und einige oberbayerische Orte, deren Ortsgruppen mehr zufällig aufgrund privater Initiativen einzelner Hitler-Anhänger entstanden. Die erste solche Ortsgruppe außer-

${ }^{27}$ Helmut K. Anheier u. Friedhelm Neidhardt, Soziographische Entwicklung der NSDAP in München 1925 bis 1930, in: München - „Hauptstadt der Bewegung“, S. 179-186, hier S. 179.

${ }^{28} \mathrm{Vgl}$. dazu Auerbach, Hitlers politische Lehrjahre, S. 28, Anmerkung 118.

${ }^{29}$ Donald Morse Douglas, The Early Ortsgruppen: The Development of National Socialist Local Groups 1919-1923, Diss. phil., Kansas State University 1968, S. 270; zur Zusammensetzung der Münchner Ortsgruppe speziell Donald M.Douglas, The Parent Cell: Some Computer Notes on the Composition of the First Nazi Party Group in Munich, 1919-21, in: CEH 10 (1977), S.55-72.

${ }^{30}$ Vgl. Mathias Rösch, Das Parteimilieu der NSDAP-Sektion Schwabing, in: München - „Hauptstadt der Bewegung", S. 187-188.

${ }^{31}$ Auf die Bedeutung des Stammtisches auch für die Entwicklung der frühen NSDAP haben vor allem hingewiesen: Rudy Koshar, Social Life, Local Politics, and Nazism. Marburg, 1880-1935, Chapel Hill/N.C. 1986, S.179ff.; Rudy Koshar, From Stammtisch to Party: Nazi Joiners and the Contradictions of Grass Roots Fascism in Weimar Germany, in: JMH 59 (1987), S. 1-24; Oded Heilbronner, Der verlassene Stammtisch. Vom Verfall der bürgerlichen Infrastruktur und dem Aufstieg der NSDAP am Beispiel der Region Schwarzwald, in: GG 19 (1993), S.178-201.

${ }^{32}$ Siehe M.Rainer Lepsius, Parteiensystem und Sozialstruktur. Zum Problem der Demokratisierung der deutschen Gesellschaft (zuerst 1966), in: Ders., Demokratie in Deutschland. Soziologisch-historische Konstellationsanalysen. Ausgewählte Aufsätze, Göttingen 1993, S.25-50. 
halb Münchens wurde schon am 18. April 1920 in Rosenheim gegründet ${ }^{33}$. Initiator war der Regierungsrat in der Bauinspektion der Reichsbahn, Theodor Lauböck, der durch Vermittlung eines Mitglieds des Deutschvölkischen Schutz- und Trutz-Bundes Drexlers Schrift „Mein politisches Erwachen“ bekam und mit diesem Verbindung aufnahm. Die Ortsgruppe wuchs schnell auf über 200 Mitglieder. Obwohl Rosenheim Eisenbahnwerkstätten hatte und der Anteil der Arbeiterschaft in der Bevölkerung nicht klein war, war die NSDAP-Ortsgruppe im wesentlichen mittelständisch orientiert. Ihr gehörten 19,6\% der leitenden Angestellten Rosenheims, 10,1\% der freiberuflichen Akademiker, 11,4\% der Handwerksmeister, $11,2 \%$ der Kaufleute, aber nur 3,5\% der ungelernten Arbeiter, $6 \%$ der Facharbeiter und 1,3\% der Wohlfahrtsempfänger der Stadt an. Der erste Ortsgruppenführen der Partei war allerdings ein Werkmeister. Wie in der Münchner NSDAP gab es auch in der Rosenheimer Parteiführung Meinungsverschiedenheiten über den sozialistischen Aspekt des Partei-Programms. Hitler, der 1920/21 mehrmals in Rosenheim sprach, mußte im Februar 1921 Hermann Esser und Oskar Körner nach Rosenheim schicken ${ }^{34}$, um die Ortsgruppe wieder auf die richtige Linie zu bringen. Von Rosenheim aus wurden auch schon 1920 die Parteigenossen in Kolbermoor und Bad Aibling betreut.

Die zweite auswärtige Ortsgruppe entstand im August 1920 in Starnberg. Dort wohnte der schon in Germanen-Orden und Thule-Gesellschaft aktive Dentist Friedrich Krohn, der Hitler seine Bibliothek völkischer Schriften zur Verfügung stellte ${ }^{35}$. Krohn zog sich aber schon 1921 aus Protest gegen Hitlers diktatorische Gelüste aus der Partei zurück. Wohl wegen der Nähe zu München und der kräftigen Aktivität der Münchner dort blieb Starnberg in der frühen Zeit eher eine Zahlstelle als eine eigene Ortsgruppe. Im Herbst 1920 entstand nach Landsberg am Lech und Straubing Anfang Oktober die stärkste und aktivste südbayerische Ortsgruppe in Landshut ${ }^{36}$. Ende Juli 1921 hat es in Bayern neun Ortsgruppen gegeben ${ }^{37}$, alle in Südbayern. Schwaben und Franken lagen zu dieser Zeit im Einzugsbereich der Deutschsozialistischen Partei (DSP).

Auf der NSDAP-Tagung in München am 11./12. August 1921 wurde - offensichtlich auf Wunsch einiger auswärtiger Ortsgruppenleiter - eine erste organisatorische Gliederung der Partei vorgenommen. Hitler war davon zwar nicht sehr angetan und hielt das eher für ein verbales Zugeständnis, wie spätere Briefe zeigen. Immerhin entstand bei dieser Gelegenheit eine Anschriftenliste ${ }^{38}$, die erstmals die regionale Aufteilung der NSDAP dokumentiert: Unter der „Landesleitung Bayern“ sind die Ortsgruppen München, Tegernsee, Starnberg, Landsberg, Rosenheim, Kolbermoor, Augsburg, Rothenburg ob der Tauber, Scheinfeld, Markt Bibart, Landshut, Straubing, Passau, Bernau, Amberg und Grevenbroich (!) angeführt. Zum „Landesverband Baden“ gehörten die Ortsgruppen Mannheim und Lampertheim, zum „Landesverband Württemberg“ die Ortsgruppen Stuttgart und Pforzheim. Unter dem „Landesverband Thüringen“ sind die Orts-

${ }^{33} \mathrm{Zu}$ Rosenheim vgl. die beiden Ausstellungsbände: Rosenheim in den 20er Jahren. Kleinstadtleben in Politik, Wirtschaft und Kultur, hg. v. Kulturamt der Stadt Rosenheim, Rosenheim 1986; Rosenheim im Dritten Reich. Beiträge zur Stadtgeschichte, hg. v. Kulturamt der Stadt Rosenheim, Rosenheim 1989.

${ }^{34}$ Douglas, Early Ortsgruppen, S. 87.

${ }^{35}$ Vgl. Franz-Willing, Ursprung der Hitlerbewegung, S. 115.

${ }^{36}$ Auf Landshut werden wir im Zusammenhang mit Gregor Straßer zurückkommen.

${ }^{37}$ Vgl. Douglas, Early Ortsgruppen, S. $192 \mathrm{ff}$.

${ }^{38}$ IfZ, MA 736, IV, 5 (Mikrofilm von Beständen des ehem. Hauptarchivs der NSDAP). 
gruppen Halle an der Saale und Meiningen genannt; der „Landesverband Westfalen“ bestand nur aus der Ortsgruppe Dortmund, auch Hannover bildete einen eigenen Landesverband.

Soweit in der folgenden Zeit bis November 1923 auch in anderen bayerischen Regierungsbezirken Ortsgruppen der NSDAP entstanden, gingen diese fast immer auf die Initiative einzelner zurück und hatten ihren Ursprung im Deutschvölkischen Schutz- und Trutz-Bund ${ }^{39}$. Wo die NSDAP in Schwaben und Franken Fuß fassen konnte, waren es vor allem protestantische Gemeinden, die den Anfang machten. In katholischen Gebieten entwickelte sich die Partei langsamer und später. So ging beispielsweise die Aktivität des späteren Gauleiters Dr. Hellmuth und seines völkischen Kampfbundes „Frankenland“ von dem betont protestantischen Kitzingen aus.

Auf die Ortsgruppen der NSDAP außerhalb Bayerns kann hier nur kursorisch eingegangen werden; einige besonders charakteristische Beispiele seien herausgegriffen: Fast überall sind auch dort die Ortsgruppen der NSDAP aus dem Deutschvölkischen Schutzund Trutz-Bund hervorgegangen, weniger aus der DSP. In manchen Orten, vor allem im Rhein-Ruhrgebiet, nannten sie sich nach dem Verbot der NSDAP infolge des Republikschutzgesetzes vom 21. Juli 1922 „Bund der Beobachterfreunde“, weil sie den VB weiterhin abonniert hatten. In diesen frühen Jahren waren ja, wie schon erwähnt, Doppelmitgliedschaften in mehreren völkischen Verbänden sehr häufig ${ }^{40}$.

Nach einem Auftreten Hitlers beim Schutz- und Trutz-Bund in Stuttgart soll sich dort im Mai 1920 eine "wilde“ Ortsgruppe der NSDAP gebildet haben, die aber noch ein unselbständiges Dasein führte und finanzielle Schwierigkeiten hatte. In Mannheim war der Deutschvölkische Schutz- und Trutz-Bund im Januar 1921 für die NSDAP aktiv, schwenkte aber im Februar zur DSP über mit der Begründung, die DSP sei eine echte sozialistische Partei, keine „Säbel-Rassel-Partei“. Es gab also hier Auseinandersetzungen, welche der beiden Parteien man unterstützen sollte. Hitler wollte am 5. März in Mannheim sprechen, das wurde aber verschoben und Ernst Ulshöfer aus Stuttgart als Ersatz geschickt.

${ }^{39}$ Zur Entwicklung der NSDAP in anderen bayerischen Regierungsbezirken wären vor allem folgende Arbeiten zu nennen, wobei diese vielfach Fallstudien sind, in denen die Zeit vor 1923 nur mehr oder weniger knapp behandelt wird. Zu Franken: Rainer Hambrecht, Der Aufstieg der NSDAP in Mittel- und Oberfranken (1925-1933), Nürnberg 1976; Roland Flade, „Es kann sein, daß wir eine Diktatur brauchen“. Rechtsradikalismus und Demokratiefeindschaft in der Weimarer Republik am Beispiel Würzburg, Würzburg 1983; Carsten Pollnick, Die Entwicklung des Nationalsozialismus und Antisemitismus in Aschaffenburg 1919-1933, Aschaffenburg 1984. Zur Oberpfalz bzw. Regensburg: Erich Zweck, Die Nationalsozialistische Deutsche Arbeiterpartei in Regensburg von 1922-1933, in: Verhandlungen des Historischen Vereins für Oberpfalz und Regensburg 124 (1984), S. 149-260. Zu Schwaben: Zdenek Zofka, Die Ausbreitung des Nationalsozialismus auf dem Lande. Eine regionale Fallstudie zur politischen Einstellung der Landbevölkerung in der Zeit des Aufstiegs und der Machtergreifung der NSDAP 1928-1936, München 1979. Zur Pfalz: Hans Fenske, Die Pfälzische NSDAP 1921-1932, in: Mitteilungen des Historischen Vereins der Pfalz 85 (1987), S. 347-381.

${ }^{40}$ Dazu schreibt beispielsweise einer der führenden Völkischen aus Göttingen und spätere Gauleiter der NSDAP von Hannover-Süd (1924-1928), Ludolf Haase 1942 in seinen Erinnerungen: „Woher kamen diese Männer? Ganz allgemein kann man von ihnen sagen: Aus dem völkischen Lager, denn eigentlich gehörte man damals überall hin. Alle gehörten in den ,Deutschvölkischen Schutzund Trutzbund', ebenso waren sie Mitglieder der Ehrhardt-Brigade, des NDO. (Nationalverband deutscher Offiziere) oder VNS. (Verband nationalgesinnter Soldaten), des ,Deutschen Herolds usw. Es waren immer dieselben Leute." Aufstand in Niedersachsen. Der Kampf der NSDAP 1921/24, 1. Halbband, 2. vermehrte und verbesserte Niederschrift, 1942, S. 91 (als Kopie im Niedersächsischen Hauptstaatsarchiv, Sign. Hann. 310 I G Nr.1). 
Er fungierte ab 26. Januar 1921 als Bevollmächtigter der NSDAP in Württemberg und Ba$\operatorname{den}^{41}$.

Ähnliche Spannungen gab es auch in der Ortsgruppe der NSDAP in Hannover, die im Juli 1921 ebenfalls aus dem Deutschvölkischen Schutz- und Trutz-Bund entstand ${ }^{42}$. Sie hatte anfangs nur 25 Mitglieder und suchte sich deshalb mit anderen völkischen Gruppen zu verbünden, auch mit der DSP. Von der Münchner Zentrale forderte sie Blanko-Mitgliedskarten an, um schneller Mitglieder aufnehmen zu können. Das wurde aber von dort abgelehnt. Anfang September 1921 bekam der Hannoveraner Ortsgruppenleiter Seifert einen ziemlich scharfen Brief von Hitler, er solle sich auf die eigene Ortsgruppe konzentrieren, eine Verbindung mit anderen Gruppen sei unerwünscht. Die Hannoveraner hielten sich aber nicht daran: aufgrund ihrer Bemühungen trat am 20.Januar 1922 die ganze DSP-Gruppe Hannover der NDSAP bei, die damit auf fast 100 Personen anwuchs. München blieb demgegenüber reserviert. Die Hannoveraner DSP-Mitglieder mußten individuell der NSDAP beitreten und bekamen ihre Mitgliedskarten aus München.

Soweit im Rhein-Ruhr-Gebiet 1920 bis 1922 NSDAP-Ortsgruppen entstanden, kamen deren Mitglieder ebenfalls größtenteils aus dem Deutschvölkischen Schutz- und TrutzBund. Auch sie waren hauptsächlich bürgerlicher Herkunft ${ }^{43}$. Der Leiter der ältesten, 1920 entstandenen Ortsgruppe Dortmund, Wilhelm Ohnesorge, war zum Beispiel ein Oberpostrat. Später im „Dritten Reich“ wurde er Reichspostminister. In Berlin dagegen gründeten die Freikorpsangehörigen Gerhard Roßbach, Heinz Oskar Hauenstein und Albert Leo Schlageter erst im August 1922 eine NSDAP-Ortsgruppe, nachdem sie kurz vorher Hitler in München kennengelernt hatten. Sie warben Mitglieder in zwei Ablegern des Schutz- und Trutz-Bundes, der Deutschsozialistischen Partei und der Deutschsozialen Partei, die Anfang 1921 von dem alt-konservativen Berliner Antisemiten Richard Kunze gebildet worden war. Kunze verbreitete in seiner Partei auch die Schriften von Anton Drexler, so daß da schon früh geistige Beziehungen bestanden ${ }^{44}$.

Die NSDAP wurde nach der Auflösung des Deutschvölkischen Schutz- und TrutzBundes im Juli 1922 zum Sammelbecken seiner aktiven Teile - allerdings nicht lange, denn schon Mitte November 1922 wurde die NSDAP aufgrund des Republikschutzgesetzes in Preußen und in den meisten anderen deutschen Staaten in Norddeutschland verboten. Als Nachfolgeorganisation der NSDAP trat im Dezember die Deutschvölkische Freiheitspartei auf ${ }^{45}$.

Die auswärtigen Ortsgruppen wurden von der Münchner Parteizentrale hinsichtlich der Mitgliedschaft und der Finanzen am straffen Zügel gehalten. Für die Anerkennung einer neuen Ortsgruppe wurden vier Bedingungen gestellt: es mußte ein Grundstock von Mit-

${ }^{41} \mathrm{Zu}$ Stuttgart und Mannheim vgl. Douglas, Early Ortsgruppen, S. $70 \mathrm{ff}$. u. S. 238 ff.; Johnpeter Horst Grill, The Nazi Movement in Baden, 1920-1945, Chapel Hill/N.C. 1983.

${ }^{42}$ Douglas, Early Ortsgruppen, S. 177 ff.; Jeremy Noakes, The Nazi Party in Lower Saxony 19211933, Oxford 1971, S.16ff. und das in Anmerkung 40 zitierte Manuskript von L. Haase. In anderen norddeutschen Orten verlief die Entwicklung der NSDAP aus dem Deutschvölkischen Schutz- und Trutz-Bund sehr ähnlich. Hier sei lediglich hingewiesen auf die Beispiele Hamburg (vgl. Thomas Krause, Hamburg wird braun. Der Aufstieg der NSDAP von 1921-1933, Hamburg 1987) und Flensburg (vgl. Peter Heinacher, Der Aufstieg der NSDAP im Stadt- und Landkreis Flensburg [1919-1933], Teil 1 und 2, Flensburg 1986, hier bes. Teil 1, S. 145 ff.).

${ }^{43}$ Vgl. dazu vor allem Wilfried Böhnke, Die NSDAP im Ruhrgebiet 1920-1933, Bonn 1974; Lohalm, Völkischer Radikalismus, S.317ff.

${ }^{44}$ Bernd Kruppa, Rechtsradikalismus in Berlin 1918-1928, Berlin 1988, bes. S. $137 \mathrm{ff}$.

${ }^{45}$ Dazu Reimer Wulff, Die Deutschvölkische Freiheitspartei 1922-1928, Diss. phil., Marburg 1968. 
gliedern vorhanden sein, diese mußten die Bedingungen anerkennen, die auf dem Aufnahme-Antrag genannt waren, die Ortsgruppe mußte ausreichende finanzielle Unterstützung aus den eigenen Reihen bekommen, die monatlichen Abrechnungen und Berichte der lokalen Gruppen mußten nach München geschickt werden. Die Mitglieder hatten außerdem deutscher Abstammung zu sein und monatlich mindestens 50 Pfennig Mitgliedsbeitrag an die Zentrale zu zahlen, ab Januar 1921 auch nochmals denselben Betrag für die Unterstützung des VB. Die Ortsgruppen außerhalb Münchens waren ansonsten auf sich selbst gestellt und bekamen keine Unterstützung aus München ${ }^{46}$. Finanzielle Beihilfe leistete die Parteizentrale in dieser Zeit nur an zwei bayerische Ortsgruppen: Landshut und Passau. Dagegen wurden innerhalb Bayerns von der Münchner Zentrale häufig Propagandaredner gestellt.

In den ersten Jahren ihres Bestehens waren die Bemühungen der NSDAP fast gänzlich auf Bayern beschränkt. Die Entstehung der Ortsgruppen außerhalb Bayerns förderte man nicht. Hitler vertrat gegenüber der Parteileitung den Standpunkt, nicht die Zahl, sondern die Leistungsfähigkeit der Ortsgruppen sei ausschlaggebend ${ }^{47}$. Vor Juli 1921 trat Hitler selbst nur einmal als Redner außerhalb Bayern auf, und zwar im Mai 1920 in Stuttgart vor dem Schutz- und Trutz-Bund, Hermann Esser dagegen mehrmals. Er trug die Hauptlast als Propagandist außerhalb Münchens. Nach dem Juli 1921 wurde Esser der Propaganda-Chef der NSDAP.

\section{Die Deutschsozialistische Partei}

Etwa zur gleichen Zeit wie die DAP in München entstand auch im nördlichen Teil Deutschlands aus der alldeutsch-völkischen Gemengelage eine neue Partei, die betont sozialistisch sein wollte, "völkisch links“ - in Abgrenzung zum „Herrenstandpunkt" der Alldeutschen und Deutschnationalen. Der altvölkische Düsseldorfer Ingenieur Alfred Brunner ${ }^{48}$ verbreitete im Dezember 1918 mit Hilfe des "Germanen-Ordens“ einen Entwurf (später Denkschrift) „zur Gründung einer deutsch-sozialistischen Partei auf judenreiner und kapitalloser Grundlage“. Im Laufe des nächsten Jahres entstanden unabhängig voneinander in mehreren Städten deutschsozialistische Parteigruppierungen. Ende 1919 gab es solche Ortsgruppen oder Arbeitsgemeinschaften in Düsseldorf, Kiel, Frankfurt am Main, Dresden, Nürnberg und München. Die Münchner Gruppe, im Oktober 1919 entstanden, wurde von zwei Redakteuren des „Münchener Beobachter“, Hans Georg Grassinger und Max Sesselmann, geleitet, in dessen Räumen (Thierschstraße 15) befand sich auch die Geschäftsstelle der Partei. Die DSP in München hatte 1921300 bis 400 Mitglieder, blieb also wesentlich kleiner als die NSDAP. Sie löste sich im Spätherbst 1922 auf. Die Mitglieder gingen größtenteils zur NSDAP ${ }^{49}$.

Die Deutschsozialistische Partei besaß von Anfang an eine dezentrale Struktur. Auf einem Parteitag in Hannover am 24./25. April 1920 wählte man zwar Brunner als geistiges Oberhaupt der Bewegung zum „Obmann“, den Vorsitz übernahm aber ein anderer. Ab Mitte November 1920, nachdem Berlin zur Zentrale der Partei bestimmt worden war, wurde dies der Berliner Lehrer Emil Holtz. Der Vorstand blieb schwach, die DSP hatte

\footnotetext{
${ }^{46} \mathrm{Vgl}$. Douglas, Early Ortsgruppen, S. $118 \mathrm{f}$.

${ }^{47}$ Siehe die diesbezüglichen Zitate Hitlers bei Franz-Willing, Ursprung der Hitlerbewegung, S. 262 f.

${ }^{48} \mathrm{Zu}$ Alfred Brunner und die DSP vgl. Tyrell, Vom ,Trommler` zum ,Führer', S.65ff.

${ }^{49}$ Zeugenschrifttum Grassinger (wie Anm. 8); vgl. auch Gilbhard, Thule-Gesellschaft, S. $154 \mathrm{ff}$.
} 
aber im Herbst 1920 immerhin schon 35 Ortsgruppen und ca. 2000 Mitglieder. Die Ortsgruppen waren relativ selbständig, die Kräfte dadurch zersplittert. Aber man verstand sich als Partei, wollte sich im Unterschied zu Hitler an Wahlen beteiligen und war, wenn auch mit Einschränkungen, demokratisch organisiert; die Meinungsbildung erfolgte durch Abstimmungen. Die DSP vertrat einen Legalitätskurs und war gegen Umsturz und Gewaltmaßnahmen. Sie entwickelte kein umfassendes Programm, Brunners Denkschrift diente als Richtlinie. Anton Drexler kannte sie, denn sie war unter dem Titel „Unser politisches Programm“ am 31. Mai 1919 im „Münchener Beobachter“ abgedruckt worden. Der Redakteur Sesselmann war ja einer der Leiter der Münchner Ortsgruppe der DSP, die aber angesichts der Konkurrenz der Hitlerpartei 1920/21 immer mehr ein Schattendasein führte. Sesselmann bemühte sich deshalb auch um eine Fusion zwischen DSP und NSDAP.

Eine Gegenüberstellung der Brunnerschen Denkschrift und des Drexler-Hitlerschen Parteiprogramms zeigt viel Übereinstimmung ${ }^{50}$. Beide bieten einen Querschnitt durch den prononciert „antikapitalistischen“ Teil des völkischen Ideenkonglomerats. Die Brunnersche Denkschrift war stärker wirtschaftspolitisch ausgerichtet, das NSDAP-Programm in vielen Punkten rigoroser. Auch die DSP sah ihre Hauptaufgabe in der „Aufklärung der Öffentlichkeit“, war aber für eine Daueragitation im Stile Hitlers viel zu schwach und auch nicht rabiat genug. Die Leitung der DSP auf Reichsebene war sehr bürgerlich (Akademiker, höherer Mittelstand), großenteils altgediente Völkische aus der Vorkriegszeit. In der NSDAP waren die Leute jünger, gehörten dem unteren Mittelstand an und vertraten radikalere Forderungen.

Die Unterschiede in der Mentalität der führenden Vertreter beider Parteien traten bei den Fusionsabsichten offen zu Tage. Offizielle Verhandlungen scheiterten meist. Aber viele Ortsgruppen der DSP wurden ab Herbst 1922 durch bloße Umbenennung Keimzellen der NSDAP; die Mitglieder mußten sich aber individuell in die NSDAP aufnehmen lassen. Diese Ortsgruppen bestanden nicht lange unter diesem Namen. Am 18. November 1922 wurde die NSDAP in Preußen verboten, die meisten Länder folgten diesem Beispiel. Die NSDAP-Ortsgruppen firmierten nun unter dem Namen „Großdeutsche Arbeiterpartei“.

Die Deutschsozialisten hatten schon 1919 Verbindung zur Deutschen Nationalsozialistischen Arbeiterpartei in Wien aufgenommen, die seit 1903 in der K.u. K. Monarchie bestand. Die DNSAP hatte auch schon früh Kontakte mit der Müncher DAP. Sie lud die Bruderparteien zu einem gemeinsamen "großdeutschen Parteitag“ ein, der Anfang August 1920 in Salzburg stattfand ${ }^{51}$. An ihm nahmen Vertreter der Deutschsozialisten, der NSDAP, der österreichischen und der böhmischen DNSAP teil. Drexler und andere hatten die Vorstellung von einer lockeren Föderation aller nationalsozialistischen Parteien über die Reichsgrenzen hinweg. Man konnte sich darüber aber nicht einigen und schuf lediglich eine „Salzburger Kanzlei“ als gemeinsame Koordinationsstelle, die auch das nächste Treffen arrangieren sollte, das man immerhin in Aussicht nahm. Auch eine Verschmelzung der beiden deutschen Parteien war geplant. Vorerst wurde aber nur eine regionale Aufteilung vereinbart: die NSDAP sollte auf Bayern, Württemberg und Baden beschränkt bleiben. Darüber kam es aber bald zu Reibereien. Julius Streichers DSP-Gruppe in Nürnberg wollte unabhängig bleiben bzw. sich nicht der Münchner NSDAP anschlie-

${ }^{50}$ Ein Vergleich der beiden Programme bei Tyrell, vom ,Trommler' zum ,Führer', S. $76 \mathrm{ff}$.

${ }^{51} \mathrm{Zu}$ den Kontakten zur DNSAP und zum Salzburger Treffen vgl. ebd., S. $95 \mathrm{ff}$.; Douglas, Early Ortsgruppen, S. $52 \mathrm{ff}$. 
ßen und auch ihren Einflußbereich in Franken behalten. Vor allem Hitler hatte Vorbehalte gegen eine solche föderative Partei. Die Deutschsozialisten sahen in dem "fanatischen Gernegroß" Hitler den hauptsächlichen Störenfried. Auf dem nächsten Föderationsparteitag in Zeitz im März 1921 nahm Hitler nicht teil, sondern nur Drexler, der aber keine Vollmachten des Parteivorstands hatte. Der in Zeitz ausgearbeitete Kompromiß einer Fusion von DSP und NSDAP wurde unter dem Druck des maßlos verärgerten Hitler zwei Wochen später am 14. April von den Münchnern torpediert. Hitler betrachtete so etwas als „Kapitulation“. Das Problem der Fusion oder Abweisung der DSP schob er weiter vor sich her; er war in dieser Frage unsicher und entschlußlos.

\section{Julius Streicher in Franken}

Schon in Salzburg hatte man eine bemerkenswerte Ausnahme gemacht: Die starken deutschsozialistischen Ortsgruppen in Franken, meist mehr oder weniger fest unter der Führung Streichers, sollten bestehenbleiben. Im vorwiegend protestantischen Mittel- und Oberfranken hatte der Deutschvölkische Schutz- und Trutz-Bund von Anfang an eine starke Position, bildete zahlreiche Ortsgruppen und entfaltete eine rege antisemitische Agitation. Der Schutz- und Trutz-Bund wurde auch hier zur Basis der Deutschsozialistischen Partei. Deren Nürnberger Ortsgruppe wurde im November 1919 gegründet. Der Volksschullehrer Julius Streicher ${ }^{52}$ trat ihr im Januar 1920 bei. Schon im April 1920 wurde er Mitglied des Reichsvorstands der DSP und mit der Herausgabe der ab Juni 1920 erscheinenden Parteizeitung „Deutscher Sozialist“ betraut. Auch aus dem Schutz- und Trutz-Bund kommend, war Streicher ein Kenner der antisemitischen Literatur, stark von Theodor Fritsch beeinflußt, und kannte viele Leute aus dem völkischen Lager. Streicher führte ein sehr selbstherrliches Regime und war auf seine Unabhängigkeit bedacht. Die Nürnberger Ortsgruppe der DSP wuchs schon im Sommer 1920 auf über 300 Mitglieder an. Streicher hat in der DSP eine ähnliche Stellung eingenommen wie später Hitler in der NSDAP. Daraus ergab sich eine mehr oder weniger offene Rivalität zwischen beiden um die Führung der süddeutschen Antisemiten ${ }^{53}$.

Als der "Deutsche Sozialist“ im Herbst 1921 in finanzielle Schwierigkeiten kam, half ihm Otto Dickel in Augsburg aus. Streicher ging nun mit der ganzen DSP-Ortsgruppe Nürnberg (damals an die 800 Mitglieder) zu Dickels „Deutscher Werkgemeinschaft“ über und nannte seine Zeitschrift in „Deutscher Volkswille“ um. Nach einem Jahr war Streicher wieder in Geldnöten und kam wegen der Schulden mit Dickel in Streit. Die Deutsche Werkgemeinschaft hatte inzwischen auch an Popularität verloren, da der „Deutsche Volkswille“ für den Metallarbeiterstreik eintrat. Dickel gefiel der heftige Antisemitismus Streichers nicht. Streicher trat am 19. September aus der Deutschen Werkgemeinschaft aus. Am 8. Oktober 1922 schrieb er an Hitler und bot sich diesem samt seiner Zeitschrift und seinen zahlreichen Anhängern in Franken an. Streicher erreichte von Hitler die Übernahme seiner Schulden und eine Anleihe von 70000 Mark für die Erhaltung

${ }^{52} \mathrm{Zu}$ Streicher vgl. vor allem Robin Lenman, Julius Streicher and the Origins of the NSDAP in Nuremberg, 1918-1923, in: Anthony Nicholls u. Erich Matthias (Hg.), German Democracy and the Triumph of Hitler, London 1971, S. 129-159; Carol J. Ehlers, Nuremberg, Julius Streicher and the Bourgeois Transition to Nazism, 1918-1924, Part I, II, Diss. phil., Univ. of Colorado 1975; Hambrecht, Aufstieg der NSDAP in Mittel- und Oberfranken (siehe Anm.39).

${ }^{53}$ Vgl. ebd., S. 23. 
des „Deutschen Volkswillens“. Er verkaufte sich also praktisch an die NSDAP. Diese hatte inzwischen beim "Deutschen Tag“ in Coburg am 14./15. Oktober $1922^{54}$ einen großen Propaganda-Erfolg erzielt. Es war das erste Mal, daß die NSDAP zusammen mit der SA (mehr als 600 Leute) massiv außerhalb Münchens auftrat, und es war der entscheidende Durchbruch der Partei in Nordbayern. Im Laufe der nächsten Tage und Wochen entstanden dort in vielen Orten neue Stützpunkte der NSDAP. Vielfach gingen DSP-Ortsgruppen geschlossen zur NSDAP über.

Wenige Tage nach dem effektvollen SA-Auftritt in Coburg gründete Streicher in Nürnberg eine NSDAP-Ortsgruppe in Anwesenheit Hitlers. Der größere Teil seiner DSP-Leute folgte ihm. Die neue Nürnberger Ortsgruppe der NSDAP wuchs schnell und gewann ihre Anhänger hauptsächlich aus dem seit langem antisemitisch gesinnten kleinen Mittelstand Frankens, nicht zuletzt dank Streichers rabiater Reden und Pamphlete. Damit hatte er ja schon Dickel und andere maßvollere Kreise des völkischen Lagers vor den Kopf gestoßen. Als er am 20. April 1923 die erste Nummer des „Stürmer“ herausbrachte, rief diese auch bei der Münchner Parteileitung Bestürzung hervor. Streicher provozierte in Nürnberg laufend Prozesse gegen sich, die er bewußt als Propagandamittel einsetzte. Auch innerhalb der Nürnberger NSDAP-Ortsgruppe gab es ständig Streitigkeiten, so mit dem Chefredakteur des „Deutschen Volkswillens“, Walter Kellerbauer, den Streicher selbst im Sommer 1922 auf Empfehlung Dickels eingesetzt hatte und der von Amann in München gestützt wurde. Hitler war nicht in der Lage, die innerparteilichen Nürnberger Querelen zu schlichten. Erstmals tauchte damit das Problem auf, wie auf selbständige Entscheidungen pochende regionale Teile der NSDAP von der inzwischen die ganze Autorität fordernden Münchner Zentrale geführt werden konnten, wenn die Partei nicht in einzelne Fragmente zerfallen sollte. Streichers Gefolgsleute in Nürnberg dachten tatsächlich an eine Trennung von München. Erst im Sommer 1923 konnte ein Kompromiß geschlossen werden: Streicher bekam in Nürnberg beträchtliche Freiheit in der Parteiführung und Propaganda, Kellerbauer mußte die Parteizeitung abgeben. Die Münchner Parteizentrale erlangte dafür eine effektive Kontrolle der Nürnberger SA. Am 16. August 1923 schrieb Amann an Streicher, jetzt, da er ja die fränkische Parteizeitung in seiner Regie habe, sei doch eigentlich kein Bedarf mehr am „Stürmer" vorhanden ${ }^{55}$. Alle überregionalen Publikationen und Propagandamaterialien sollten unter der direkten Leitung der Münchner Zentrale stehen. Damit kam er aber bei Streicher schlecht an. Der „Stürmer“ blieb in Streichers Händen und erschien weiter in der gleichen Art als antisemitisches Hetzblatt.

Der Verlauf des „Deutschen Tages“ in Nürnberg am 1./2. September $1923^{56}$ wurde aber ein persönlicher Erfolg Hitlers und das Vorbild für die späteren Reichsparteitage der NSDAP. Bei dieser Gelegenheit - es war gleichzeitig der „Sedantag“ - nahmen neben Prinz Ludwig Ferdinand von Bayern, Theodor Fritsch, General Erich Ludendorff und zahlreichen anderen Generalen und Offizieren die Führer der „vaterländischen“ Verbände in Bayern teil. Aus NSDAP, „Bund Oberland“ und „Reichsflagge“ bildete sich der „Deutsche Kampfbund“.

${ }^{54} \mathrm{Zu}$ den Coburger Ereignissen siehe Jürgen Erdmann, Coburg, Bayern und das Reich 1918-1923, Coburg 1969; Nicholas F. Hayward u. D.S. Morris, The First Nazi Town, New York 1988.

${ }^{55} \mathrm{Vgl}$. Lenman, Julius Streicher, S. $149 f$.

${ }^{56}$ Siehe Der Hitler-Putsch. Bayerische Dokumente zum 8./9. November 1923, hg. v. Ernst Deuerlein, Stuttgart 1962, S. 166 f.; Auerbach, Hitlers politische Lehrjahre, S. 39. 


\section{Otto Dickel in Augsburg}

Auch in Augsburg verlief die Entwicklung der nationalsozialistischen Bewegung in den Anfangsjahren nicht im Sinne der Münchner Führung. Ab 1919 war hier der Deutschvölkische Schutz- und Trutz-Bund aktiv, gefördert vor allem durch den Fabrikanten Dr. Gottfried Grandel" ${ }^{57}$, der zugleich Dietrich Eckarts Zeitschrift „Auf gut deutsch" finanziell unterstützte und im März 1920 das Flugzeug besorgte, mit dem Eckart und Hitler während des Kapp-Putsches nach Berlin flogen. Grandel trat im August 1920 der NSDAP bei und zog andere Völkische mit sich. Wie schon erwähnt, spielte er beim Erwerb des VB durch die NSDAP eine wichtige Rolle als Bürge. Hitler zeigte sich dadurch erkenntlich, daß er bei den ersten größeren Werbeveranstaltungen der Augsburger NSDAP als Hauptredner auftrat. Wie einer der Teilnehmer berichtete, waren dabei fast „lauter Doktoren, Ingenieure usw., nur keine Arbeiter“ zugegen. Schon beim ersten Mal, am 12. Januar 1921, sprach in der Diskussion der Augsburger Studienrat Dr. Otto Dik$\mathrm{kel}^{58}$. Hitler fand wenig Gefallen an Dickels politischen Äußerungen und verließ Augsburg in schlechter Laune. Eine zweite und letzte Veranstaltung der NSDAP in diesem Jahr fand am 10. Mai statt, mit Hitler als Hauptredner und Esser als Versammlungsleiter.

Dickel war auch Mitglied der NSDAP, gründete aber im März 1921 eine eigene Organisation, nämlich die „Deutsche Werkgemeinschaft“, die zwar für eine „wahrhaft deutsche Volksverfassung" mit Ständecharakter und ohne Parteien und für ein auf „germanischer Wesensart" basierendes deutsches Recht kämpfte, im übrigen aber durchaus sozial- und lebensreformerische Vorstellungen und eine Bodenreform in Anlehnung an Adolf Damaschke vertrat. Dickels Antisemitismus war sehr viel gemäßigter als der Hitlers und Streichers. Anfang 1921 veröffentlichte Dickel einen Anti-Spengler, ein Buch mit dem Titel „Die Auferstehung des Abendlandes. Die abendländische Kultur als Ausfluß des planetarischen Weltgefühls“. Dickel war nach seiner naturwissenschaftlichen Promotion lange Jahre in China und Indien gewesen, hatte also eine größere Welterfahrung als die meisten $\mathrm{Na}$ tionalsozialisten. Auch schuf er 1922 im Norden Augsburgs auf einem Moorgrundstück eine Siedlung für Kleingärtner und Kleintierzüchter, die heute noch besteht und den $\mathrm{Na}$ men „Dickelsmoor“ trägt. Dickels Werkgemeinschaft machte der NSDAP in Augsburg in den Jahren 1921/22 eine starke und erfolgreiche Konkurrenz.

Dickel und seine Werkgemeinschaft hatten auch gute Beziehungen zu gewissen Gewerkschaftskreisen in Augsburg, die der USPD nahestanden und eher nationalbolschewistische Ziele vertraten. In ihnen sah er den Werkgemeinschaftsgedanken in Ansätzen realisiert. Erster Vorsitzender der Augsburger Werkgemeinschaft war nicht Dickel selbst, sondern ein Carl Böhrer, von Beruf Eisendreher und in der Räterepublik 1919 Volkskommissar für das Wohnungswesen. Ende März 1922 befürwortete Dickel öffentlich den Streik der Augsburger Metallarbeiter. In derselben Versammlung mit etwa 2500 Leuten sprach auch Streicher und hielt eine seiner üblichen antisemitischen Hetzreden, was Dickel nur

${ }^{57}$ Vgl. Tyrell, Vom ,Trommler' zum ,Führer', S. 110 u. S. 255.

${ }^{58}$ Ebd., S. 110 ff.; Bayer. Hauptstaatsarchiv, M Inn 737320, Wochenberichte d. Regierungspräsidenten, bes. vom 3.4. 1922 (darin auch das Programm der Deutschen Werkgemeinschaft); Gerhard Hetzer, Die Industriestadt Augsburg. Eine Sozialgeschichte der Arbeiteropposition, in: Bayern in der NSZeit, Bd.III, hg., v. Martin Broszat u.a., München 1981, S.1-233, hier S. 51 f.; Gerhard Hetzer, Von der Reichsgründung bis zum Ende der Weimarer Republik 1871-1933, in: Günther Gottlieb u.a. (Hg.), Geschichte der Stadt Augsburg von der Römerzeit bis zur Gegenwart, Stuttgart 1984, S. 568-592, hier S. $588 \mathrm{f}$. 
noch mehr Schwierigkeiten brachte; seine nächsten Veranstaltungen wurden verboten. Trotzdem sprach Dickel bald darauf auch in Nürnberg; bis Oktober dieses Jahres gehörten ja Streicher und seine Leute zur Deutschen Werkgemeinschaft. Dickel war Hitler geistig weit überlegen; er war auch ein guter Redner und konnte seine Überzeugungen vehement vortragen, zudem hatte er ebenfalls ein starkes Sendungsbewußtsein. Hitler spürte in ihm einen ernsthaften Rivalen.

\section{Hitler wird Parteiführer}

Anfang Juni 1921 verließ Hitler München auf unbestimmte Zeit, um in Berlin Geldmittel für den vor dem Konkurs stehenden VB aufzutreiben. Zur Überbrückung seiner Abwesenheit lud die Parteileitung Otto Dickel als Redner nach München ein. Kurz vorher war sein Buch vom „Völkischen Beobachter" sehr empfohlen worden. Am 24. Juni sprach Dikkel im Hofbräuhaus-Festsaal „mit größtem Erfolg“. Man dachte, in ihm einen zweiten zugkräftigen Redner neben Hitler gefunden zu haben. Am 10. Juli 1921 trafen sich Abordnungen der Münchner Nationalsozialisten und der Nürnberger Deutschsozialisten mit Dickel in Augsburg zur „Vorbesprechung einer Einigung“. Überraschend platzte da Hitler in großer Erregung in die Besprechung, um eine solche Einigung zu verhindern - er war offensichtlich von Esser laufend über die Geschehnisse informiert worden. Als Dikkel mit seinen Vorstellungen einer Reform des Parteiprogramms bei Eckart, Drexler und Lauböck auf Gegenliebe stieß, wurde Hitler wütend und verließ die Tagung. Am folgenden Tag erklärte er seinen Austritt aus der Partei. In seiner umfangreichen Austrittserklärung vom 14. Juli 1921 wettert Hitler vehement gegen Dickel, zitiert aus dessen Buch, vermeidet es aber, Dickels Namen zu nennen ${ }^{59}$.

Nach Vermittlung durch Eckart kapitulierte der Partei-Ausschuß einige Tage später, um seinen erfolgreichen Werbe-Obmann nicht zu verlieren. Hitler stellte sechs Bedingungen für seinen Wiedereintritt in die Partei ${ }^{60}$ :

1. forderte er den Posten des ersten Vorsitzenden mit „diktatorischer Machtbefugnis zu sofortiger Zusammenstellung eines Aktionsausschusses, der die rücksichtslose Reinigung der Partei von den in sie eingedrungenen fremden Elementen durchzuführen hat".

2. Sitz der Bewegung müsse immer München bleiben.

3. Jegliche Namens- oder Programmänderung solle unterbleiben „ein für allemal zunächst auf die Dauer von sechs Jahren“.

4. Jede Fusion mit der DSP solle unterbleiben.

5. Jegliche Verhandlungen in dieser Hinsicht dürften nur mit seiner persönlichen Einwilligung stattfinden.

6. Der für August in Linz geplante Parteitag solle nicht besucht werden.

Wie Albrecht Tyrell plausibel dargelegt hat, entsprang dieses Vorgehen Hitlers eher einer Affekthandlung angesichts des drohenden Verlustes der Ausnahmestellung seiner Agita-

${ }^{59}$ Hitlers Austrittserklärung und seine Äußerungen über Dickel siehe Hitler, Sämtliche Aufzeichnungen 1905-1924, hg. v. Eberhard Jäckel. Stuttgart 1980, S. $436 \mathrm{ff}$.

${ }^{60}$ Siehe dazu Tyrell, Vom ,Trommler' zum ,Führer', S.116ff. Zur innerparteilichen Entwicklung ab Sommer 1921 vgl. auch Wolfgang Horn, Führerideologie und Parteiorganisation in der NSDAP (1919-1933), Düsseldorf 1972 (2. Aufl.: Der Marsch zur Machtergreifung. Die NSDAP bis 1933, Königstein/Ts. 1980). 
tionstätigkeit und nicht etwa einer vorgeplanten Taktik zur Durchsetzung eines diktatorischen Führungsanspruchs über die Partei. Hitler ging es um die Durchsetzung seiner Vorstellungen vom politischen Kurs der Partei. Die innerparteiliche Organisation überließ er seinen Vertrauten. Der ehemalige Feldwebel Max Amann schien ihm dafür der geeignetste Mann.

Eine zum 29. Juli 1921 einberufene Mitgliederversammlung der NSDAP demonstrierte die Unterordnung der Partei unter die Führung Hitlers. Dabei kam der auf dieser Versammlung verabschiedeten Satzung erhebliche Bedeutung zu. Sie setzte das von Hitler verlangte "diktatorische Prinzip“ durch. Nach ihm war die neue Führungsstruktur der Parteispitze ausgerichtet: die verantwortliche Leitung der Partei lag ausschließlich bei deren Erstem Vorsitzenden. Hitler stand nun über dem Leitungs-Ausschuß. Anton Drexler wurde zum „Ehrenvorsitzenden“ der Partei ernannt und damit vom Entscheidungsprozeß ausgeschaltet. Entsprechend dem „diktatorischen Prinzip“ waren nun demokratische Gepflogenheiten wie Abstimmungen in der NSDAP verpönt. Hitler bemühte sich in der Folgezeit um eine Straffung der Parteiorganisation. Er wollte die auswärtigen Ortsgruppen stärker in den Griff bekommen, auch dort sollten autoritäre Organisationsmaxime gelten und die einzelnen Ortsgruppen der Parteizentrale untergeordnet sein. Das gelang verhältnismäßig leicht bei den südbayerischen Ortsgruppen, die auf Hitler ausgerichtet waren. Sehr viel langsamer und schwieriger erreichte man das dagegen bei den weiter entfernten Ortsgruppen im Norden und außerhalb Bayerns, die ja vielfach ganz unabhängig von Hitler und der Münchner Zentrale entstanden waren. Die meisten dieser Ortsgruppen beharrten bis 1923 beim herkömmlichen Vereinsstil. Dem Zweck einer Stabilisierung der Partei diente auch die erste Generalmitgliederversammlung der NSDAP vom 30. Januar 1922. Es war das erste Mal, daß Vertreter auswärtiger Ortsgruppen in größerer Zahl in München zusammentrafen; 718 Vertreter auswärtiger Gruppen und 200 Münchner Parteimitglieder nahmen daran teil. Eine geschickte Regie verstand es, den Teilnehmern den Eindruck geschlossener Einigkeit in der Partei zu vermitteln. Otto Dickel, den Hitler in seiner Austrittserklärung als „extremsten Gegner" der Partei bezeichnet hatte, wurde in einem Rundschreiben der Parteileitung vom 10. September 1921 aus der NSDAP ausgeschlossen. Eine hitlertreue NSDAP-Ortsgruppe entstand in Augsburg aber erst im Oktober 1922 auf Initiative des Stadtamtmanns Dr. Adolf Frank. Bis weit in das Jahr 1923 hinein blieb Otto Dickels Werkgemeinschaft in Augsburg die bestimmende völkische $\mathrm{Kraft}^{61}$.

${ }^{61}$ Der Wortlaut des Rundschreibens Nr. 4 mit dem Ausschluß Dickels in: Führer befiel ... Selbstzeugnisse aus der "Kampfzeit" der NSDAP. Dokumentation und Analyse, hg. v. Albrecht Tyrell, Düsseldorf 1969, S.29ff. Dickel hat sich nach seinem Ausschluß aus der NSDAP immer weiter von Hitler entfernt. Wegen seiner negativen Einstellung zum Nationalsozialismus wurde er im Oktober 1934 für zehn Monate inhaftiert und mußte aus dem Schuldienst ausscheiden. Die Deutsche Werkgemeinschaft e.V. wurde 1933 "gleichgeschaltet", das heißt der Vorstand mit NSDAP-Mitgliedern besetzt. Dickel hatte in den Kriegsjahren Kontakte zu Oppositionskreisen. Nachdem er sich im Frühjahr 1944 mit Gesinnungsgenossen in Karlsruhe getroffen hatte, wurde er bald darauf an seinem damaligen Wohnort im Kreis Reutlingen von der Gestapo aufgesucht. Kurz vor seiner Verhaftung gelang es ihm, sich auf einer Toilette mit einer Pistole das Leben zu nehmen. Für die Überlassung von Unterlagen über Dickel und dessen Werkgemeinschaft dankt der Verfasser sehr dem Stadtarchivar von Friedberg, Herrn Georg Kerle. 


\section{Gregor Straßer in Landshut}

Nach Streicher/Nürnberg und Dickel/Augsburg soll noch auf eine dritte nationalsozialistische Figur, die schon vor November 1923 in Bayern regionale Bedeutung erlangte und nicht zur Entourage um Hitler gehörte, kurz hingewiesen werden: auf Gregor Straßer in Landshut, der schon bald nach seinem Eintritt in die NSDAP zum wichtigsten Mann der Partei in Niederbayern wurde. Das Bild von seinen Anfängen in der NSDAP blieb lange getrübt durch die Legenden, die seine Brüder Otto und Paul in die Welt gesetzt hatten ${ }^{62}$.

Die Ortsgruppe Landshut der NSDAP ist am 4. Oktober 1920 gegründet worden; sie gehörte neben Rosenheim und Passau zu den aktivsten der frühen Zeit. Von hier aus wurden zahlreiche weitere Ortsgruppen in Niederbayern gegründet. Auch in der Landshuter NSDAP überwog der untere Mittelstand. 1922 hatte die Partei dort ca. $34 \%$ Facharbeiter, Handwerker und Inhaber kleinerer Geschäfte, fast 32\% waren Beamte, Angestellte und Akademiker, nur $0,9 \%$ Soldaten und Offiziere, $1,8 \%$ ungelernte Arbeiter. Der „Gedankenaustausch“ zwischen der Ortsgruppe und der Münchner Zentrale war in dieser Zeit auch hier recht einseitig: „Der Willensbildungsprozeß wurde von oben herab vollzogen. Nur selten übte eine Ortsgruppe Kritik an der Parteileitung in München. Dem ,Brieftagebuch', einem Verzeichnis der bei der Parteigeschäftsstelle ein- und ausgehenden Briefe mit stichwortartigen Inhaltsangaben, ist als eine der wenigen Ausnahmen eine Kritik von seiten der Ortsgruppe Landshut zu entnehmen. Im März 1921 hatte sich Landshut beschwert, da verschiedene Widerrufungen, die die NSDAP nach einigen Reden durch Urteile vornehmen mußte, eine ,schädliche Wirkung' hätten." ${ }^{\text {"63 }}$

Hitler selbst hatte diese Angelegenheit „persönlich erledigt“. Er besuchte Landshut Ende Februar und Ende März 1921. Daß er bei einer solchen Gelegenheit im Hause Straßer erstmals mit Ludendorff zusammengetroffen sei, ist aber ein Märchen ${ }^{64}$. Gregor StraBer trat erst im Oktober 1922 der NSDAP und der SA bei. Bald danach wurde er stellvertretender Vorsitzender der Ortsgruppe, im März 1923 Führer der Sturmabteilung Niederbayern der SA. Beim SA-Aufzug am 1. Mai 1923 in München vertrat er mit Oberstleutnant Kriebel zusammen einen harten Kurs und wollte Hitler vom Einlenken gegenüber Reichswehr und Polizei abhalten. Am Putschversuch des 9. November war er nur am Rande beteiligt. Er hatte lediglich die Wittelsbacher Brücke besetzt zu halten und zog am Abend unbehelligt mit seinen SA-Leuten wieder nach Landshut ab; dort sind sie entwaffet worden. Straßer wurde erst im Februar 1924 verhaftet und stand beim zweiten Prozeß gegen die Putschisten am 2. Mai vor Gericht; er bekam eine Haftstrafe auf Bewährung. Obwohl er damals in Untersuchungshaft saß, wurde er am 6. April 1924 als Abgeordneter des Völkischen Blocks in den Bayerischen Landtag gewählt. Gregor Straßer verhielt sich in den frühen Jahren Hitler gegenüber völlig loyal.

\section{Die SA als Propagandainstrument}

Auf der Mitgliederversammlung der NSDAP am 29. Juli 1921 wurde auch die Organisation einer Turn- und Sport-(Sturm-)Abteilung beschlossen, deren Zweck im Schutz der Versammlungen, in der Abstellung des Sicherungs- und Ordnungsdienstes und der gegen-

${ }^{62}$ Dazu jetzt Gabriele Goderbauer, Gregor Straßer und die Anfänge der NSDAP in Bayern, inbesondere in Niederbayern und Landshut, Bd. 1 und 2, unveröff. Mag.-Arbeit München 1986.

${ }^{63}$ Ebd., Bd.1, S. 82 f.

${ }^{64}$ Ebd., S. 87. 
seitigen Unterstützung bei gefährdeten Versammlungen bestand. Die Aufstellung dieser Sturmabteilung, bald kurz SA genannt, war ein persönliches Anliegen Hitlers. Nach seiner Ansicht sollte sie auch eine wesentliche propagandistische Funktion haben. Sie sollte gleichzeitig „Sturmbock“ der nationalsozialistischen Bewegung wie „Trägerin des Wehrgedankens" sein. Ihr Aufbau wurde dem Leutnant a.D. Ulrich Klintzsch aus der „Organisation Consul“ des Kapitäns Ehrhardt anvertraut ${ }^{65}$. Der Stab der SA wurde in den ersten Monaten aus der Kasse Ehrhardts finanziert. Als im Frühjahr 1923 der im Ersten Weltkrieg berühmt gewordene Kampfflieger Hermann Göring zur NSDAP stieß, wurde ihm die Leitung der SA übertragen. Die SA-Einheiten erhielten schon unter Klintzsch eine militärische Grundausbildung und durch Vermittlung des Reichswehrhauptmanns Ernst Röhm die entsprechende Bewaffnung. Im Oktober 1921 gab es im Raum München 21 SA-Gruppen mit insgesamt 280 bis 300 Mitgliedern. Schon aus 40 bis 60 Mann wurde eine "Hundertschaft" gebildet $^{66}$. Im September 1922 gab es auch „Hundertschaften " in Freising, Landshut und Bad Tölz. Anläßlich einer Kundgebung der Vaterländischen Verbände Bayerns am 16. August 1922 fand auf dem Königsplatz in München ein erster öffentlicher Auftritt der SA mit Hakenkreuzfahnen statt. In den nächsten Wochen und Monaten dehnte sich die SA schnell im Bayern südlich der Donau, Franken und Schwaben aus. Am 11. Dezember 1922 gab es einen schweren Zusammenstoß der SA mit sozialistischen Gruppen in Göppingen ${ }^{67}$. Es war das erste Mal, daß ein geschlossener Verband der SA zur „Demonstration“ in einen Ort außerhalb Bayerns fuhr; auch ein fränkischer Verband beteiligte sich daran. Vorbild war wohl das Auftreten der SA beim „Deutschen Tag“ in Coburg drei Monate vorher. Nicht von ungefähr ging dem Aufbau der SA die Auflösung der bayerischen Einwohnerwehren und des „Freikorps Oberland“ voraus. Aus diesen Verbänden gingen viele Leute zur SA über. Die SA wurde attraktiv als nationaler Wehrverband, und die NSDAP insgesamt gewann dadurch in den nationalistischen Kreisen an Prestige und Anerkennung.

Viele SA-Einheiten führten innerhalb der NSDAP-Ortsgruppen ihr Eigenleben, und sie hielten auch zusammen, als die NSDAP in Preußen und anderen norddeutschen Staaten verboten wurde. Ab 1923 arbeitete die Parteizentrale vielfach mehr mit der SA zusammen als mit den Ortsgruppenleitungen. Die SA gewann an Eigenbewußtsein und ließ sich von einem politischen Ortsgruppenleiter nicht viel sagen. Diese Selbständigkeit der SA wurde noch dadurch begünstigt, daß die SA regional, nach militärischem Vorbild zusammengefaßt wurde, während Hitler die Bildung von Zwischeninstanzen in der politischen Gliederung damals ausdrücklich ablehnte ${ }^{68}$. Nach dem Vorbild von Coburg wurde die SA zum Aushängeschild der Partei, sie hatte schließlich die Hauptlast der Parteiaktivität zu tragen. Ihr verdankte die Partei in erster Linie ihr wachsendes Ansehen im Jahre 1923. Im Februar 1923 wurde die NSDAP dank der SA Mitglied der „Arbeitsgemeinschaft der Vaterländischen Kampfverbände“ in Bayern. Deren martialische Demonstration am 1.Mai

${ }^{65} \mathrm{Zu}$ Klintzsch und den Anfängen der SA vgl. Heinrich Bennecke, Hitler und die SA, München 1962, S. 28 f.; Andreas Werner, SA und NSDAP. SA: „Wehrverband“, „Parteitruppe“ oder „Revolutionsarmee“? Studien zur Geschichte der SA und der NSDAP 1920-1933, Diss. phil., Erlangen 1964; zu Ernst Röhms Bedeutung für die SA siehe auch Peter Longerich, Die braunen Bataillone. Geschichte der SA, München 1989.

${ }^{66} \mathrm{Vgl}$. Werner, SA und NSDAP, S. 47.

${ }^{67}$ Dazu ebd., S. $61 \mathrm{f}$.

${ }^{68}$ Die Selbständigkeit der SA wird besonders hervorgehoben bei Douglas, Early Ortsgruppen, S.278ff.; Wolfgang Schieder, NSDAP vor 1933 (Anm. 29), S. $148 \mathrm{f}$. 
1923 gegen die Versammlung der Arbeiterbewegung endete zwar in einem Fiasko, aber der „Deutsche Tag“ in Nürnberg am 1./2. September 1923 brachte einen gewissen Ausgleich, denn Hitler stand nun gleichberechtigt neben dem nationalen Heros, General Ludendorff. Wie schon erwähnt, wurden bei dieser Gelegenheit auf Betreiben Hitlers und Röhms NSDAP, Bund Oberland und Röhms Wehrverband „Reichsflagge“ zum „Deutschen Kampfbund" zusammengeschlossen, der bald darauf, am 8./9. November 1923, den bekannten Putsch versuchte, der kläglich scheiterte und der NSDAP ein vorläufiges Ende bereitete, das allerdings kaum mehr als ein Jahr dauerte. Eines der wenigen auswärtigen NSDAP-Mitglieder, die an dem Putschversuch aktiv teilnahmen, war Julius Streicher, der vor dem Münchner Rathaus unter dem Schutz eines Stroßtrupps eine PropagandaRede hielt und an der Feldherrnhalle in der ersten Reihe des Demonstrationszuges mitmarschierte, ohne verwundet zu werden. Er sollte in der geplanten "provisorischen Nationalregierung " Hitlers die Redner-Propaganda leiten.

Beim Prozeß gegen Hitler und die Hauptbeteiligten des Putsch-Versuches im Februar und März 1924 konnte der Führer der NSDAP nochmals einen persönlichen Propaganda-Erfolg einheimsen, dessen Auswirkungen sich einen Monat später bei den bayerischen Landtagswahlen zeigten: der „Völkische Block“ wurde im Stadtgebiet München zur stärksten Partei: er errang $35 \%$ der Stimmen. Der Völkische Block wurde mit 17,1\% auch zur zweitstärksten Partei in Bayern. Nicht viel besser sah es bei den Reichstagswahlen im Mai 1924 aus: in ganz Bayern erreichte der Völkische Block 16,0\% (nach Mecklenburg war das der zweithöchste Stimmenanteil, auf Reichsebene blieben es 6,6\%), in München 28,5\%, in Mittelfranken $24,7 \%$, in Niederbayern $18,7 \%$, in der Oberpfalz $9,8 \%{ }^{69}$.

Hitler war durch den Prozeß gegen ihn keineswegs ausgeschaltet, er hatte weiterhin eine große Anhängerschaft in München, das gleiche galt für Julius Streicher in seinem Agitationsbereich Mittelfranken.

In Reaktion auf die linke Revolution von 1918/19 war die „Ordnungszelle Bayern“ zum Refugium der Rechten in Deutschland geworden. Die völkisch-nationalistischen Gruppen und Parteien konnten sich hier ungestört entwickeln, von den national-konservativ eingestellten Regierungen Kahr und Knilling nicht nur geduldet, sondern eher gefördert. Auf bayerischem Boden, in Bamberg, war 1919 der Deutschvölkische Schutz- und TrutzBund entstanden. Aus ihm rekrutierten sich sowohl die Deutschsozialistische Partei, in der Julius Streicher eine große Rolle spielte, wie die (Nationalsozialistische) Deutsche Arbeiterpartei, die bald von Adolf Hitler beherrscht wurde. Beide Parteien hatten fast das gleiche Programm. Der in seiner Weltanschauung fanatischere Hitler setzte sich durch, Streicher schwenkte auf ihn ein. Trotzdem blieb eine latente Rivalität zwischen beiden noch lange bestehen. Während Hitler Dickel, Harrer, Drexler und andere ihm nicht gänzlich willfährige Parteimitglieder ausschalten konnte, mußte er Streicher Konzessionen machen.

Die Konfessionszugehörigkeit der Parteiführer innerhalb der NSDAP spielte in dieser frühen Zeit keine Rolle. Sie waren alle überzeugt völkisch gesinnt und mehr oder weniger

${ }^{69}$ Nach Dietrich Thränhardt, Wahlen und politische Strukturen in Bayern 1848-1953. Historisch-soziologische Untersuchungen zum Entstehen und zur Neuerrichtung eines Parteiensystems, Düsseldorf 1973, S.132ff.; Wolfgang Zorn, Bayerns Geschichte im 20. Jahrhundert. Von der Monarchie zum Bundesland, München 1986, S. $301 \mathrm{f}$. 
stark antisemitisch eingestellt. Man kann aber feststellen, daß der Weg vom Deutschvölkischen Schutz- und Trutz-Bund über die Deutschsozialistische Partei zur NSDAP, den viele gingen, ein Weg der Radikalisierung war.

Daß die NSDAP in München entstand und zuerst in Bayern Fuß faßte, hat mehr mit der "Ordnungszelle" zu tun als mit der Katholizität des Landes. Der Katholik Streicher hat seine ersten Erfolge unter den antisemitisch gesinnten Protestanten Mittelfrankens errungen. Auch in anderen Gebieten Bayerns waren es eher mittelständische Animositäten, ein unzufriedenes Kleinbürgertum und die allgemeine Kommunistenfurcht weiter Kreise, die der NSDAP Anhänger zuführten. Diese Stimmung war in den Städten ausgeprägter als auf dem Lande. Ähnlich lag es auch in den Orten außerhalb Bayerns. Es gab da noch weniger nationalsozialistische Ortsgruppen, deren Aktivität über Stammtisch-Gespräche hinausging. Schwerpunkte waren, soweit man in dieser frühen Zeit überhaupt schon von solchen sprechen kann, in Stuttgart, Hannover, Dortmund und einigen anderen Städten des Rhein-Ruhrgebiets.

Als Hitler anläßlich des Kapp-Putsches mit Dietrich Eckart nach Berlin geflogen war, soll er sich dem Kapitän Ehrhardt als Propaganda-Redner angeboten haben - als Reichswehrsoldat hatte er da ja schon Erfolge erzielt. Ehrhardt soll ihn aber unwirsch abgewiesen haben: Man könne ihn nicht brauchen; mit seiner österreichischen Aussprache könne er hier nichts erreichen. Dieser und anderer Berliner Erfahrungen eingedenk, konzentrierte sich Hitler deshalb anfangs bewußt auf die „Ordnungszelle Bayern" und scheute davor zurück, außerhalb deren Grenzen öffentlich aufzutreten. Die NSDAP ist zwar in Bayern groß geworden, das heißt aber nicht, daß man ihre Anfänge als eine speziell bayerische Angelegenheit ansehen kann. 


\section{Ursula Büttner}

\section{„Volksgemeinschaft“ oder Heimatbindung: Zentralismus und regionale Eigenständigkeit beim Aufstieg der NSDAP 1925-1933}

In keinem Bereich der Zeitgeschichte haben regional- und lokalhistorische Arbeiten eine solche Bedeutung erlangt wie bei der Erforschung des Nationalsozialismus. Hier zeichnet sich ein Trendwechsel in der Forschung ab. Regionalgeschichte hatte es in Deutschland anders als in Frankreich oder in den angelsächsischen Ländern - lange Zeit schwer, als gleichrangige sozialhistorische Methode anerkannt und beachtet zu werden. Auch bei der wissenschaftlichen Beschäftigung mit dem Nationalsozialismus dominierten zunächst die großen, auf die politischen Entwicklungen und Entscheidungen auf Reichsebene sowie die Struktur des Herrschaftssystems zielenden Gesamtanalysen. Die wegweisende, der wahlsoziologischen Forschung der zwanziger Jahre verpflichtete Arbeit von Rudolf Heberle über die Durchsetzung des Nationalsozialismus in Schleswig-Holstein ${ }^{1}$ konnte bezeichnenderweise erst 1963 aufgrund der Initiative Martin Broszats erscheinen; andere frühe Regional- oder Lokalstudien stammten überwiegend von angelsächsischen Autoren, so das berühmte Buch über Northeim von William Sheridan Allen von 1965, die Studie von Noakes über Niedersachsen (1971) und die von Pridham über Bayern (1973) ${ }^{2}$. Seit den 70er Jahren hat sich das Bild jedoch wesentlich verändert. Die Verlagerung des Interesses auf die Frage, wie der Massenerfolg der Nationalsozialisten zu erklären sei, und später die Hinwendung zur Alltagsgeschichte der „kleinen Leute“ ließen eine Fülle von Regionalstudien entstehen; denn nur im begrenzten Raum waren klare konfessionelle und sozialstrukturelle Verhältnisse, eindeutige historische Traditionen, ideologische Prägungen und politische Konstellationen zu finden, war die Interdependenz zwischen diesen Faktoren zu ermitteln.

Zwei Zielsetzungen lassen sich bei den Arbeiten zur Geschichte des Nationalsozialismus in einer Region oder Stadt unterscheiden: Zum einen soll das lokale Interesse an der eigenen Geschichte befriedigt und zum Teil durch Betroffenheit über das Geschehen in der unmittelbaren Nähe eine pädagogische Wirkung erreicht werden. Zum anderen verste-

\footnotetext{
${ }^{1}$ Rudolf Heberle, Landbevölkerung und Nationalsozialismus. Eine soziologische Untersuchung der politischen Willensbildung in Schleswig-Holstein 1918 bis 1932, Stuttgart 1963.

${ }^{2}$ William S. Allen, „Das haben wir nicht gewollt!" Die nationalsozialistische Machtergreifung in einer Kleinstadt 1930-1935, Gütersloh 1965; Jeremy Noakes, The Nazi Party in Lower Saxony 1921-1933, Oxford 1971; Geoffrey Pridham, Hitler's Rise to Power. The Nazi Movement in Bavaria, 1923-1933, London 1973. Als Vorläufer von seiten der deutschen Sozialgeschichtsforschung war 1963 die vielbeachtete Dokumentation von Werner Jochmann erschienen: Nationalsozialismus und Revolution. Ursprung und Geschichte der NSDAP in Hamburg 1922-1933, Frankfurt/M. 1963. Es folgten als relativ frühe deutsche Arbeiten mit zehnjährigem Abstand: Eberhart Schön, Die Entstehung des Nationalsozialismus in Hessen, Meisenheim 1972 und Wilfried Böhnke, Die NSDAP im Ruhrgebiet, 1920-1933, Bonn-Bad Godesberg 1974.
} 
hen die Autoren ihre Untersuchungen als „Fallstudien“, deren exemplarische Ergebnisse die generelle Kenntnis über die Entstehungs- und Wirkungsbedingungen des Nationalsozialismus erweitern sollen. Die Regionalstudie sei „ein Baustein zur Gesamtgeschichte der NSDAP ${ }^{\star 3}$, so oder ähnlich äußern sich die meisten Autoren. Das erkenntnisleitende Interesse gilt nicht der Region, sondern die regionale Begrenzung ist das Mittel, um zu fundierten allgemeingültigen Aussagen zu gelangen. Sehr deutlich wird das bei der historischen Wahlforschung ${ }^{4}$. Die Umschreibung der „Region“ wird bei diesen Arbeiten durch das Forschungsinteresse bestimmt: Es sind Räume, die sich durch ihre spezifische wirtschaftliche und soziale Struktur, die konfessionelle Prägung, die geschichtliche Erfahrung und die Identifikation der Bewohner mit der näheren Umgebung von anderen unterscheiden und zugleich - das ist bei der Frage nach den Gründen für politisches Verhalten unerläßlich und zwingt oft zu Kompromissen - als politische Einheiten (Länder, Wahlkreise) faßbar sind.

$\mathrm{Da}$ es bei den wissenschaftlichen Untersuchungen primär um den Nationalsozialismus und nur sekundär um die Geschichte der Region geht, fanden Gebiete das meiste Interesse, in denen die NSDAP besonders große Wahlerfolge erzielte oder in denen sie ungewöhnlich schlecht abschnitt. Gebiete mit durchschnittlichen Ergebnissen, wie z.B. die Provinz Brandenburg (Potsdam I + II), das Weser-Ems-Gebiet um Bremen, Sachsen (Dresden, Leipzig) und Baden, wurden dagegen verhältnismäßig wenig beachtet.

Die vielen inzwischen vorliegenden Regionalstudien und die ebenfalls auf regionaler Detailanalyse basierende Wahlforschung bestätigen eine Reihe von Aussagen, die sich aufgrund sorgfältiger Interpretation von Einzelbeobachtungen auch schon in der älteren Literatur finden ${ }^{5}$ : Die Wiedergründung der NSDAP 1925 erfolgte überall durch einzelne einheimische Aktivisten; von ihren Fähigkeiten und ihrem Einsatz hing in den nächsten drei bis vier Jahren die Entwicklung der Partei ab. Erst nach dem Anwachsen zur Massenpartei seit 1929/30 sind für die jeweilige Region typische Unterschiede in der Geschichte der NSDAP zu erkennen. Die wichtigsten sollen kurz genannt werden:

Ihre weitaus besten Ergebnisse erzielten die Nationalsozialisten nach 1929 in evangelischen Landgebieten wie Schleswig-Holstein, Hannover, Braunschweig, Oldenburg, Hessen, Ober- und Mittelfranken, und zwar besonders in den Dörfern sowie den Klein- und Mittelstädten ${ }^{6}$. In eindrucksvollem Gegensatz dazu blieben sie in eingesprengten katholischen Landesteilen, z.B. dem Oldenburger Münsterland (Vechta, Cloppenburg), dem Raum um die Bistümer Fulda oder Limburg und Unterfranken, weit hinter dem Reichsdurchschnitt zurück. Selbst Nachbardörfer wählten völlig verschieden: evangelische Dörfer im Fuldaer Raum zu 90 bis 100\% Hitler bei der Reichspräsidentenwahl 1932, katholische Dörfer dagegen zu 90 bis 100\% den Protestanten Hindenburg7. In evangelischen

${ }^{3}$ Böhnke, Ruhrgebiet, S. 12.

${ }^{4}$ Jürgen W.Falter, Hitlers Wähler, München 1991.

${ }^{5}$ So bei Gerhard Schulz, Aufstieg des Nationalsozialismus. Krise und Revolution in Deutschland, Frankfurt/M. u. a. 1975, S.355-398.

${ }^{6}$ Vgl. u. a. Falter, Hitlers Wähler, S. 163, S.175-188.

${ }^{7}$ Dies kann z. B. Klaus Schönekäs für die Kreise Gersfeld und Hünfeld im Raum Fulda nachweisen: Klaus Schönekäs, „Christenkreuz über Hakenkreuz und Sowjetstern". Die NSDAP im Raum Fulda, in: Eike Hennig (Hg.), Hessen unterm Hakenkreuz. Studien zur Durchsetzung der NSDAP in Hessen, Frankfurt/M. 1983, S. 127-179, hier S. 140; das gleiche Bild ergibt sich bei einer Gegenüberstellung der katholischen und protestantischen Ämter in Oldenburg, vgl. die Graphik bei Klaus Schaap, Die Endphase der Weimarer Republik im Freistaat Oldenburg 1928-1933, Düsseldorf 1978, S.288. 
Landgebieten gab es kein ähnlich festgefügtes Sozialmilieu wie im katholischen Bereich, so daß der Wechsel der parteipolitischen Präferenzen leichter möglich war. Überall verloren die konservativen und liberalen bürgerlichen Parteien zwischen 1924 und 1928 einen Großteil ihrer Wähler an wirtschaftliche Interessenparteien (die Bauern an die Christlichnationale Bauern- und Landvolkpartei, den gewerblichen Mittelstand an die Wirtschaftspartei) oder auch an regionale Sonderparteien wie die Welfenpartei in Hannover; und da diese weder die Folgen der Agrarkrise noch die als vernichtend erlebte Regierungspolitik abzuwenden vermochten, wanderten die Wähler seit 1929 weiter zur radikalsten Protestpartei, der NSDAP. Günstige Voraussetzungen für die Aufnahme der NS-Ideologie hatten überall die Verbände geschaffen: die völkischen und nationalen Organisationen, die Wehrverbände und Kriegerbünde, die Heimat- und Kulturvereine und besonders die angeblich unpolitischen Berufsverbände.

Bei näherem Zusehen in den Regionen zeigen sich jedoch viele Unterschiede: Der Zusammenhang zwischen antisemitischer Indoktrination und der Anfälligkeit für nationalsozialistische Parolen scheint auf der Hand zu liegen. Tatsächlich machte die NSDAP in Hessen die größten Fortschritte in Bezirken, in denen um die Jahrhundertwende die Antisemitenpartei des Dr. Böckel ihre Hochburgen gehabt hatte (Marburg-Frankenberg, Regierungsbezirk Kassel, Oberhessen $)^{8}$. In Schleswig-Holstein dagegen, wo die Antisemiten um Friedrich Raab ebenfalls eine starke Position gehabt und 1898 ein Reichstagsmandat erobert hatten, gab es keine solche Kontinuität. 80\% ihrer Wähler waren in Angeln im Landkreis Flensburg beheimatet gewesen; gerade hier aber konnte sich die NSDAP erst sehr viel später durchsetzen als in der übrigen Provinz, nämlich erst $1932^{\circ}$. Der Grund war in der sozialen Abschottung der standesbewußten Großbauern von den kleinen ländlichen Gewerbetreibenden und Landarbeitern zu suchen. Für die Bauern Angelns war die NSDAP noch 1930 eine „linke“, „sozialistische“ Partei, die ihren Besitz bedrohte und mit deren Anhängern sie sich nicht gemein machen wollten. Soziale Barrieren waren in diesem Fall stärker als ideologische Affinitäten.

Sehr unterschiedlich war auch die Rolle der Agrarverbände in den verschiedenen Regionen des Reichs; aber nirgendwo in den evangelischen Landgebieten - mit der einen Ausnahme Württembergs - hielten sie den Zulauf zur NSDAP auf ${ }^{10}$. Ganz ohne Mitwirkung der Verbände, spontan von der Basis her, entstand in Schleswig-Holstein auf dem ersten Höhepunkt der Agrarkrise Anfang 1928 die Landvolkbewegung; durch immer militantere Formen des Protests bis hin zu Bombenanschlägen und anderen direkten Angriffen auf die Staatsgewalt bereitete sie den radikalsten Kämpfern gegen das System, den Nationalsozialisten, den Weg. In Oldenburg und Niedersachsen sicherten sich die Landbünde Einfluß auf die Bewegung ${ }^{11}$, und in den übrigen Teilen Nord- und Ostdeutschlands übernahmen sie selbst die Führung des Protests, aber nicht gegen die NSDAP, sondern indem sie ihre eigenen Forderungen immer mehr radikalisierten und die vorzeitige "Gleichschaltung" seit 1931 hinnahmen (Wahl von Nationalsozialisten in Landbundvorstände und Landwirt-

${ }^{8}$ Schön, Hessen, S. 8-15, S. 97, S. 179.

9 Peter Heinacher, Der Aufstieg der NSDAP im Stadt- und Landkreis Flensburg (1919-1933), Flensburg 1986, Bd.1, S.55-68, S.77, S.336, S.332, S. 346.

${ }^{10}$ In diesem Abschnitt folge ich Jürgen Bergmann u. Klaus Megerle, Protest und Aufruhr der Landwirtschaft in der Weimarer Republik (1924-1933). Formen und Typen der politischen Agrarbewegung im regionalen Vergleich, in: Jürgen Bergmann u.a., Regionen im historischen Vergleich. Studien zu Deutschland im 19. und 20. Jahrhundert, Opladen 1989, S. 200-287.

11 Schaap, Oldenburg, S. 34-39. 
schaftskammern). Mehr Widerstandskraft zeigten allein die Bauernvereine im katholischen Westen und Süden Deutschlands. Trotz aller Unzufriedenheit gingen ihre politischen Forderungen nicht über einen maßvollen Verfassungswandel im Sinne des Präsidialsystems hinaus. Sie waren Teil des insgesamt resistenten katholischen Sozialmilieus.

Völlig aus dem Rahmen fiel dagegen Württemberg ${ }^{12}$. Obwohl in dem Land, dessen Bewohner zu $68 \%$ evangelisch waren und $\mathrm{zu} 41 \%$ in der Landwirtschaft arbeiteten, alle strukturellen Voraussetzungen gegeben waren, die sonst den Aufstieg der NSDAP begünstigten, lagen ihre Wahlergebnisse immer, sogar noch im März 1933, beträchtlich unter dem Reichsdurchschnitt. Als Gründe für diese Sonderentwicklung lassen sich eine ganze Reihe von Faktoren anführen: die Stärke eines bodenständigen Liberalismus, die Stabilität der Regierungsverhältnisse und das relativ gute Funktionieren des parlamentarischen Systems, der desolate Zustand der nationalsozialistischen Organisation und die Tatsache, daß die auf eine vielseitige Veredelungswirtschaft eingestellten bäuerlichen Familienbetriebe flexibler auf die Agrarkrise reagieren konnten als die Landwirtschaft im Norden und Osten Deutschlands. Unklar ist noch, welche Bedeutung der besonderen Prägung des Protestantismus, nämlich der Stärke eines Laienfrömmigkeit und basiskirchliches Engagement fördernden Pietismus, zukommt. Auffallend ist jedenfalls, daß die "Württembergische Sozietät" im Dritten Reich ein Zentrum kirchlicher Resistenz bildete und daß besonders viele württembergische Pfarrer an Bemühungen zur Rettung von Juden beteiligt waren ${ }^{13}$. Wie das Beispiel zeigt, ist die Funktion der evangelischen Kirche im Aufstiegsprozeß des Nationalsozialismus noch näher zu klären: Vermochte sie nur keine Schranke gegen ihn aufzurichten, oder förderte sie eine für ihn günstige Mentalität? Es scheint, daß dort, wo ein starkes protestantisches Sozialmilieu bestand, es das Vordringen des Nationalsozialismus ebenfalls behinderte. Hier ist weitere Arbeit nötig. Eines aber läßt sich schon heute sagen: Eine einfache Rückführung der nationalsozialistischen Erfolge auf konfessionelle und sozialstrukturelle Faktoren, so zeigt sich in Württemberg, ist nicht möglich. Die NSDAP erzielte zwar in evangelischen Agrarregionen ihre besten Ergebnisse, aber nicht alle diese Gebiete waren in gleicher Weise für ihre Agitation anfällig.

Soweit einige Ergebnisse der vergleichenden Beobachtung von Schwerpunktgebieten der NSDAP. Wenden wir uns nun der Betrachtung der für sie schwierigen Regionen zu. Auch in ihnen lassen sich einige generelle Trends erkennen:

Das katholische Sozialmilieu behinderte den Aufstieg des Nationalsozialismus durchweg am stärksten. Wie immer die Gebiete sonst strukturiert waren, im überwiegend katholischen Teil Deutschlands blieben die Wahlergebnisse der NSDAP weit unter dem Durchschnitt ${ }^{14}$. Am schwersten hatte sie es in den Dörfern und kleinen Städten, wo eine starke

12 Thomas Schnabel, Die NSDAP in Württemberg 1928-1933. - Die Schwäche einer regionalen Parteiorganisation, in: Ders. (Hg.), Die Machtergreifung in Südwestdeutschland. Das Ende der Weimarer Republik in Baden und Württemberg 1928-1933, Stuttgart u.a. 1982, S. 49-80; Detlef Mühlberger, Hitler's Followers. Studies in the sociology of the Nazi movement, London u. New York 1991, S. 50-83. Vgl. auch Roland Müller, Stuttgart zur Zeit des Nationalsozialismus, Stuttgart 1988, S. 12-24.

${ }^{13}$ Hinweise bei Theodor Dipper, Die Evangelische Bekenntnisgemeinschaft in Württemberg 19331945. Ein Beitrag zur Geschichte des Kirchenkampfes im Dritten Reich, Göttingen 1966. Über ein ${ }_{n} N e t z$ " von evangelischen Pfarrhäusern in Württemberg, in denen Juden und Christen jüdischer Abstammung zeitweise Unterschlupf fanden, berichten Ute Klingemann u. Jürgen W. Falter, Hilfe für Juden während des Holocaust. Sozialpsychologische Merkmale der nichtjüdischen Helfer und Charakteristika der Stituation, in: Günther B. Ginzel ( $\mathrm{Hg}$.), Mut zur Menschlichkeit. Hilfe für Verfolgte während der NS-Zeit, Köln 1993, S.115-145, insbes. S.127f.

${ }^{14}$ Falter, Hitlers Wähler, S. 169-188. 
Sozialkontrolle abweichendes Verhalten und auch abweichende Wahlentscheidungen mit Sanktionen belegte. Aber auch in den großen Städten wirkte das kirchliche Verdikt gegen den Nationalsozialismus, wenn auch in geringerem Maße. Wo sich freilich einmal ein katholischer Pfarrer offen zur NSDAP bekannte, brauchte sie um ein gutes Wahlergebnis in dem Dorf nicht zu fürchten ${ }^{15}$, und als die Bischöfe 1933 ihre Ablehnung des Nationalsozialismus aufgaben, verlor das katholische Sozialmilieu viel von seiner Resistenzkraft.

Eine weitere alte These wird durch die Regional- und Wahlforschung bestätigt: Neben dem Katholizismus bildete die sozialistische Arbeiterbewegung das zweite Sozialmilieu, das dem Werben der Nationalsozialisten widerstand, wenn auch nicht mit gleicher Sicherheit und im gleichen Ausmaß, wie vor allem die Untersuchungen Falters und seiner Gruppe ergaben ${ }^{16}$. Die Arbeiterschaft insgesamt war unter den Wählern und Mitgliedern der NSDAP zwar unterrepräsentiert, aber doch ziemlich stark vertreten. Landarbeiter gaben ihr überproportional häufig die Stimme, und es gab besonders 1932 auch Wechselwähler, die von der SPD und KPD zur NSDAP stießen, darunter wie Schaap für Oldenburg feststellte, nicht nur - tendenziell - weniger klassenbewußte gewerbliche Arbeiter, sondern seit 1931 auch Metallarbeiter ${ }^{17}$.

Dieser Befund widerspricht der früher vorherrschenden Auffassung, daß die NSDAP ihren Aufstieg hauptsächlich der „Panik im Mittelstand“, der Unterstützung von Bauern, selbständigen Gewerbetreibenden, Beamten und Angestellten, verdankte. Die These wird noch von einer anderen Seite her in Frage gestellt: Die bisher angenommene besondere Affinität der Angestellten zum Nationalsozialismus läßt sich nach den Untersuchungen von Falter und anderen wahlstatistisch nicht nachweisen ${ }^{18}$. Für Hamburg, die Stadt mit dem größten Angestelltenanteil unter allen deutschen Großstädten (28,3\% gegen 27\%), bin ich allerdings $\mathrm{zu}$ einem anderen Ergebnis gekommen ${ }^{19}$. Trotzdem ist Falter in einem Punkt recht zu geben: Es sind sehr viel differenziertere Arbeiten über die Angestelltenschaft nötig, die auch regionale Unterschiede berücksichtigen. Der Deutschnationale Handlungsgehilfenverband (DHV), der als ideologischer Wegbereiter des Nationalsozialismus bisher die meiste Beachtung gefunden hat, war offenbar vor allem in den Kleinund Mittelstädten zuhause (1930: 400000 Mitglieder in ca. 2000 Ortsgruppen). In der nach Übersee gewandten Großstadt Hamburg konnte der sozialistische Zentralverband der Angestellten ( $\mathrm{ZdA}$ ) ebenso viele und der liberale Gewerkschaftsbund der Angestell-

${ }^{15}$ Gerhard Paul, Die NSDAP des Saargebietes 1920-1935. Der verspätete Aufstieg der NSDAP in der katholisch-proletarischen Provinz, Saarbrücken 1987, S. 209.

${ }^{16}$ Falter, Hitlers Wähler, S. 198-230; Mühlberger, Hitler's Followers, S. 26-49; Schön, Hessen, S. 181; Böhnke, Ruhrgebiet, S. 180; Schönekäs, Christenkreuz, S.144; Heidi Fogel u. Dieter Rebentisch, Organisation und Struktur der NSDAP in südhessischen Arbeiterwohngemeinden 1928-1932, in: Henning, Hessen unterm Hakenkreuz, S. 318-349; Jürgen Pastowski, Auf dem Weg in die Katastrophe. Wahlen im Gebiet der heutigen Stadt Gelsenkirchen 1924-1930, in: Heinz-Jürgen Priamus (Hg.), Deutschlandwahn und Wirtschaftskrise. Gelsenkirchen auf dem Weg in den Nationalsozialismus. Teil 1: Die antidemokratische Allianz formiert sich, Essen 1991, S.13-74.

${ }^{17}$ Schaap, Oldenburg, S.148f.; vgl. auch Ingrid Buchloh, Die nationalsozialistische Machtergreifung in Duisburg. Eine Fallstudie, Duisburg 1980, S. 30.

${ }^{18}$ Falter, Hitlers Wähler, S. 232-241.

${ }^{19}$ Hierzu und zum folgenden Ursula Büttner, Hamburg in der Staats- und Wirtschaftskrise 19281931, Hamburg 1982, S.295-298, S.310-312, S.326f. Auch die Arbeit von Michael Prinz, Vom neuen Mittelstand zum Volksgenossen. Die Entwicklung des sozialen Status der Angestellten von der Weimarer Republik bis zum Ende der NS-Zeit, München 1986, insbes. S. $82 \mathrm{f}$. weist in die von mir am Beispiel Hamburgs beschriebene Richtung. 
ten (GdA) mehr als doppelt so viele Mitglieder an sich binden wie der DHV. Beide, auch der GdA, das ist gegen Priamus zu betonen ${ }^{20}$, gingen bis zum Ende der Weimarer Republik keine Kompromisse mit dem Nationalsozialismus ein, trotzdem ist eine Abwendung der Mitglieder nicht festzustellen. Ihre überdurchschnittlich guten Wahlresultate in Angestelltenwohngebieten verdankte die NSDAP außer jungen DHV-Mitgliedern hauptsächlich den vielen unorganisierten und erwerbslosen Angestellten.

Um die relative Stärke oder Schwäche der NSDAP zu ergründen, sind trotz der Breite der vorliegenden Regionalforschung noch weitere Studien über Gebiete mit anderen sozialen Strukturen und historischen Erfahrungen erforderlich, z.B. über weltmarktorientierte Handelsregionen wie Hamburg - gab es in ihnen auch anderswo ein der NSDAP hinderliches liberales Sozialmilieu? - oder über mitteldeutsche Länder, wie Thüringen und Sachsen, die in den Anfangsjahren der Republik reine Linksregierungen erlebt hatten und später rechte Hochburgen wurden. Insgesamt betreffen die Unterschiede aber nur Tempo und Ausmaß der nationalsozialistischen Erfolge. Mit gewissen zeitlichen Verschiebungen setzte sich die NSDAP überall durch. Wie es ihr gelang, Menschen aus allen sozialen Schichten in der "Volkspartei des Protests" ${ }^{\text {"21 }}$ zu sammeln, so war sie auch in allen Regionen auf dem Vormarsch.

Diese Feststellung führt uns zu der Frage, ob durch die Untersuchung der NSDAP-Geschichte nach Regionen die Einheitlichkeit der Parteientwicklung zu sehr überdeckt und eine Eigenständigkeit der Gaue bzw. Ortsgruppen suggeriert wird, für die es in Wahrheit keinen Spielraum gab. Wir müssen deshalb das Verhältnis von Zentrale und NS-Organisationen im Land näher betrachten.

Auch in der Zeit des NSDAP-Verbots hatten an vielen Stellen Deutschlands kleine nationalsozialistische Zirkel weiterbestanden - unter vielfältigen Tarnungen -, die sich trotz notgedrungener Anlehnung an die Deutschvölkischen ausschließlich der Partei Hitlers zugehörig und verpflichtet fühlten ${ }^{22}$. Nach der Wiedergründung der NSDAP am 27. Februar 1925 waren es solche örtlichen Kräfte, die den Wiederaufbau der Organisation außerhalb Bayerns betrieben und trugen. Von München ging keine Initiative aus ${ }^{23}$; im Gegenteil beklagten die Aktivisten in Nord- und Nordwestdeutschland das Fehlen von Anweisungen

${ }^{20}$ Heinz-Jürgen Priamus, Angestellte und Demokratie. Die nationalliberale Angestelltenbewegung in der Weimarer Republik, Stuttgart 1979, S.117-131, S. 190-196, S. 203-207. Argumente für meine abweichende Bewertung bei Büttner, Staatskrise, S. 296-297 u. S. 310-312.

${ }^{21}$ So die Formulierung bei Falter, Hitlers Wähler, S.371; ebenso Mühlberger, Hitler's Followers, S.207. Auf anderem Weg, durch die Untersuchung der politischen Einstellungen und Affinitäten und der Ursachen für ihre Veränderung, bin ich 1982 zu einem entsprechenden Ergebnis gelangt: Büttner, Staatskrise.

${ }^{22}$ Dazu und zum folgenden: Schulz, Aufstieg, S. 355-375; Werner Jochmann, Die revolutionäre Kaderpartei, in: Hans-Adolf Jacobsen u. Werner Jochmann, Ausgewählte Dokumente zur Geschichte des Nationalsozialismus 1933-1945. Kommentar, Bielefeld 1966, S.27-40; Karl Dietrich Bracher, Die deutsche Diktatur. Entstehung - Struktur - Folgen des Nationalsozialismus, 7. Aufl. Köln 1993, S. 141-146; Gerhard Schildt; Die Arbeitsgemeinschaft Nord-West. Untersuchungen zur Geschichte der NSDAP 1925/26, Diss., Freiburg 1964, S. 13-49; Peter Hüttenberger, Die Gauleiter. Studie zum Wandel des Machtgefüges in der NSDAP (Schriftenreihe der Vierteljahrshefte für Zeitgeschichte 19), Stuttgart 1969, S. 13-19; Hanna Behrend, Die Beziehungen zwischen der NSDAPZentrale und dem Gauverband Süd-Hannover-Braunschweig 1921-1933, Frankfurt/M. u. Bern 1981, S.49-74; Schön, Hessen, S.33-53; Böhnke, Ruhrgebiet, S.54-86; Noakes, Lower Saxony, S. 25-43; Rudolf Rietzler, "Kampf in der Nordmark “. Das Aufkommen des Nationalsozialismus in Schleswig-Holstein (1919-1928), Neumünster 1982, S. 187-234, S.343-365.

${ }^{23}$ Dies betont sehr stark Rietzler, Nordmark, S. 204. 
für die Gestaltung der Satzung, für die Agitation und die programmatische Arbeit. Hilfesuchende Briefe nach München blieben meistens ohne Antwort. Hitler war die Entwicklung der NSDAP außerhalb Bayerns zwar keineswegs gleichgültig, wie die Tatsache zeigt, daß er Gregor Straßer noch vor der offiziellen Wiedergründung der Partei mit ihrem Aufbau in Norddeutschland beauftragte. Straßer begriügte sich aber damit, den äußeren Rahmen abzustecken: die von regionalen Gremien gewählten Gauleiter im Namen Hitlers zu bestätigen, die Gaugrenzen festzulegen, bei Kompetenzkonflikten schlichtend einzugreifen und vor allem als attraktiver Redner bei unzähligen Versammlungen die Bemühungen der Gaue und Ortsgruppen zu unterstützen ${ }^{24}$. Die geforderte engere und permanente Verbindung nach München konnte er nicht gewährleisten, dafür war der zentrale Parteiapparat damals noch nicht leistungsfähig genug.

Das Defizit an zentraler Leitung versuchten die NSDAP-Führer in Nord- und Westdeutschland auszugleichen, indem sie nach eigenem Gutdünken agitierten und organisierten. Die nordwestdeutsche NSDAP erhielt dadurch zeitweilig ein gewisses eigenes Gepräge, das in der Forschung zum Teil stark betont wird ${ }^{25}$ : In Regionen mit einer starken Industriearbeiterschaft wie dem Ruhrgebiet wurde die "sozialistische“ Komponente des Programms herausgestrichen, in Landgebieten wie Schleswig-Holstein und Niedersachsen gab es erste Ansätze für eine Agrarpropaganda ${ }^{26}$. Manche Führungskräfte zeigten nationalrevolutionäre Tendenzen und einige Sympathien für den Nationalbolschewismus. Es kam zu organisatorischen Besonderheiten, z. B. im März 1926 zum selbständigen Zusammenschluß der Gaue Westfalen und Rheinland-Nord zum Großgau Ruhr und - noch bemerkenswerter - zur kollektiven Leitung dieses Gaus durch ein Triumvirat: Goebbels, Kaufmann und Pfeffer v. Salomon, die allerdings schon drei Monate später durch die Wahl Kaufmanns zum alleinigen Gauleiter im Beisein Hitlers beendet wurde ${ }^{27}$. Bei alledem wollten die beteiligten Nationalsozialisten aber nicht die NSDAP verändern, sondern im Sinne Hitlers handeln, dessen Willen sie mangels klarer Anweisung erahnen mußten. Selbst die "Arbeitsgemeinschaft der nord- und nordwestdeutschen Gauleiter" war kein Oppositionszentrum, sondern der Versuch, die vermißte zentrale Koordination und Leitung der Parteiarbeit durch überregionale Zusammenarbeit zu ersetzen. Heftige Angriffe gegen die „Münchener Bonzen“ und auch der Vorschlag, die Parteileitung nach Elberfeld zu verlegen $^{28}$, richteten sich gegen das Versagen des Parteiapparats, nicht Hitler. Das Ziel war nicht weniger Zentralismus, sondern die Intensivierung der Zusammenarbeit mit der Zentrale. Als Hitler bei der Bamberger Gauleitertagung am 14. Februar 1926 die Bemühungen der Nordwestdeutschen desavouierte, Programmdiskussionen untersagte und am 1.Juli alle Arbeitsgemeinschaften in der NSDAP verbot, fügten sich die Zurechtgewiesenen sofort ${ }^{29}$.

Das innerparteiliche „Führerprinzip“ wurde festgeschrieben und mit der Ernennung Goebbels' zum Gauleiter von Berlin zum 1. November 1926, der Absetzung des stellver-

${ }^{24}$ Schildt, Arbeitsgemeinschaft, S. 42-49; Udo Kissenkoetter, Gregor Straßer und die NSDAP, Stuttgart 1978, S.29-31; Volker Franke, Der Aufstieg der NSDAP in Düsseldorf. Die nationalsozialistische Basis in einer katholischen Großstadt, Essen 1987, S. 99 f.; Böhnke, Ruhrgebiet, S. 91-110.

${ }^{25}$ Am nachdrücklichsten von Reinhard Kühnl, Die nationalsozialistische Linke 1925-1930, Meisenheim 1966; differenzierter bei Schildt, Arbeitsgemeinschaft; Behrend, Beziehungen, S.104-136.

${ }^{26}$ Buchloh, Duisburg, S.48 f.; Schildt, Arbeitsgemeinschaft, S. 58-95, S. 126-130; Kühnl, Nationalsozialistische Linke, S. 64-79. Rietzler, Nordmark, S.402-405; Noakes, Lower Saxony, S. 104-106.

${ }^{27}$ Böhnke, Ruhrgebiet, S. 106-109, S. 116-119. Hüttenberger, Gauleiter, S. 33-38.

${ }^{28}$ Franke, Düsseldorf, S. 107.

${ }^{29}$ Dazu inbes. Schildt, Arbeitsgemeinschaft, und Hüttenberger, Gauleiter, S. 26-38. 
tretenden schlesischen Gauleiters Rosikat im Frühjahr 1927 und vielen anderen Personalentscheidungen Hitlers in die Tat umgesetzt. Die Entsendung des Rheinländers Goebbels nach Berlin war symptomatisch für den ein gutes Jahr nach der Wiedergründung in der NSDAP herrschenden Zentralismus. Während die ersten gewählten Gauleiter noch überwiegend aus den Regionen stammten, spielte die Herkunft bei Hitlers Entscheidung keine Rolle. Für ihn zählten allein Leistung und Loyalität. Hitler ließ den regionalen Führern Spielraum für eigenständiges Handeln, solange sie Erfolg hatten und seine Pläne nicht durchkreuzten. Wenn das geschah, griff er aber rücksichtslos durch, ohne auf nennenswerten Widerstand in den regionalen Parteiorganisationen zu stoßen.

Nach der Ernennung Goebbels' zum Reichspropagandaleiter im April 1930 wurde auch die gesamte politische Werbearbeit zentral zusammengefaßt und geleitet. In einer Anweisung vom 5. August 1930 hieß es: „Die Reichspropaganda-Abt. hat die Wahlpropaganda für das ganze Reich einheitlich gestaltet, wodurch der größtmögliche Erfolg erzielt wird. Überall in ganz Deutschland kleben dieselben Schrift- und Bildplakate, werden dieselben Flugblätter verteilt und tauchen dieselben Klebezettel auf. Das Volk wird systematisch bearbeitet. Die Sektionen treiben deshalb keine Wahlpropaganda auf eigene Faust und verzichten auf die Herstellung eigenen Werbematerials" ${ }^{* 30}$. So geschah es nicht nur bei dieser, sondern bei allen Wahlen mindestens seit 1930. Sogar für Kommunalwahlen wurden die Plakate zentral hergestellt und bei Bestellung nur die jeweilige Listennummer der NSDAP eingesetz $\mathrm{t}^{31}$. Auf lokale oder regionale politische Ereignisse oder spezifische historisch-kulturelle Traditionen konnte diese Propaganda nicht eingehen. Genau wie bei der mündlichen Agitation, die ja zu einem großen Teil von reichsweit eingesetzten, zugkräftigen Wanderrednern getragen wurde, blieb es bei den allgemeinen Schlagworten und Parolen: Kampf gegen die "Young-Sklaverei“, gegen "Marxismus" und Liberalismus, gegen die angeblich korrupten und verlogenen „Systemparteien“ und vor allem gegen den Inbegriff alles Schlechten: die Juden ${ }^{32}$. Es gab Werbematerial für die verschiedenen Berufsgruppen, das in deren Hochburgen gezielt verteilt wurde, aber keines für die einzelnen Regionen.

Die mythische Überhöhung des Preußentums, die im Dritten Reich solche Bedeutung erlangte, spielte in der NS-Propaganda dieser Zeit offenbar noch keine große Rolle ${ }^{33}$. Allein

${ }^{30}$ Archiv der Forschungsstelle für die Geschichte des Nationalsozialismus in Hamburg, Fasc. Nr.9114, Prop. Rundschreiben Nr.16 der Propaganda-Abteilung der NSDAP-Gauleitung GroßBerlin vom 5. August 1930.

${ }^{31}$ Ebd., Rundschreiben der Reichspropagandaleitung vom 27.2. 1931.

${ }^{32}$ Dies stellt u. a. Heinacher, Aufstieg, S. 310 f., für Flensburg fest, ebenso Schaap, Oldenburg, S. 95, für Oldenburg, Franke, NSDAP in Düsseldorf, S. 55 f., für Düsseldorf, Rennspieß für Kamen (Uwe Rennspieß, Von der Weltwirtschaftskrise zur Gleichschaltung. Stadtgeschichte und Kommunalpolitik Kamens 1929-1933, Essen 1992, S. 218-223), Paul, NSDAP des Saargebietes, S.157-171, für das Saargebiet. - Die Redner der NSDAP wurden zentral in zwölfmonatigen Fernkursen der offiziellen Rednerschule der Partei unter Fritz Reinhardt (am 6. Mai 1929 als solche anerkannt) ausgebildet und von diesem seit dem 1.Juli 1928 auch in 14tägigem Abstand mit Redematerialien und dispositionen versorgt. Vgl. Kissenkoetter, Straßer, S. 58.

${ }^{33}$ Sabine Höner, Der nationalsozialistische Zugriff auf Preußen. Preußischer Staat und nationalsozialistische Machteroberungsstrategie 1928-1934, Bochum 1984, weiß über die Instrumentalisierung des Preußen-Mythos für die Zwecke der NSDAP nichts zu berichten. Goebbels operierte allerdings im Landtagswahlkampf 1932 mit der Gleichsetzung von Preußentum und Nationalsozialismus. Siehe Manfred Schlenke, Nationalsozialismus und Preußen/Preußentum. Bericht über ein Forschungsprojekt, in: Otto Büsch (Hg.), Das Preußenbild in der Geschichte. Protokoll eines Symposions, Berlin 1981, S.241-261, hier: S.248. Wie in anderen Ländern versicherten führende Nationalsozialisten außerdem, die Selbständigkeit und territoriale Unversehrtheit Preußens verteidigen zu wollen (Hö- 
die Bewohner des kleinen Landes Lippe sahen sich im Januar 1933 im Wahlkampf auf ihre große historische Vergangenheit angesprochen: Sie wurden als das "Hermannsvolk“ gefeiert, das wie einst der Cheruskerfürst für die Einheit Deutschlands und seine Befreiung von der Fremdherrschaft kämpfe ${ }^{34}$. Doch mußte der Landesleiter der NSDAP zuerst nach München reisen und Hitler für seine Idee gewinnen, bevor er sie umsetzen konnte. Im übrigen war die Landespolitik auch im lippischen Wahlkampf der NSDAP kein Thema ${ }^{35}$.

Nehmen wir noch hinzu, daß die Parlamentsarbeit der nationalsozialistischen Abgeordneten in den Ländern von München angeleitet wurde ${ }^{36}$ und daß Hitler die ersten der NSDAP zufallenden Ministerposten mit Landfremden besetzte: mit dem Pfälzer Wilhelm Frick in Thüringen und dem Schleswig-Holsteiner Anton Franzen in Braunschweig, dann wird deutlich, wie zentralistisch die NSDAP strukturiert war. Der Kompensation dienten symbolische Gesten, mit denen sie sich dem Bürgertum dennoch als bodenständige Partei empfahl: die feierliche Verleihung der Nummer des örtlichen Traditionsregiments an einen SA-Sturm, die Beteiligung der SA am Trauerzug für den ehemaligen Großherzog von Oldenburg, der gezielte Einsatz von Angehörigen der alten Herrscherhäuser im Wahlkampf oder die betonte Freude über die Anwesenheit zahlreicher Bauern in ihrer heimischen $\operatorname{Tracht}^{37}$. Alles dies war nicht mehr als ästhetisches Beiwerk des „Kampfes um die Macht“.

Die Mißachtung regionaler Traditionen wurde von den Gegnern der NSDAP als Argument gegen sie stark herausgestellt. In Oldenburg warnten die bürgerlichen Parteien vor der Landtagswahl 1931, bei einem nationalsozialistischen Sieg würden Landfremde das Staatsministerium bilden ${ }^{38}$; ein Jahr später, am 16. Juni 1932, wurde Gauleiter Carl Röver, immerhin ein Einheimischer, dennoch zum Ministerpräsidenten gewählt. In Hamburg appellierten die Regierungsparteien SPD, Staatspartei und DVP gemeinsam an das Selbstverständnis der Hanseaten, sich durch Besonnenheit und nüchterne Überlegung auszuzeichnen: „Hanseaten, gebt Euch nicht selber auf! Hat je der sein Schicksal gestaltet, der die Verantwortung anderen zugeschoben hat? Haben nicht gerade wir die Pflicht, als Freiwillige der Vernunft das Beispiel zu geben, zu warnen und vor Unheil zu bewahren, wir, in

ner, Zugriff, S. 155). Vgl. auch Hans Mommsen, Preußentum und Nationalsozialismus, in: Wolfgang Benz, Hans Buchheim, Hans Mommsen (Hg.), Der Nationalsozialismus. Studien zu Ideologie und Herrschaft, Frankfurt/M. 1993, S.29-41.

${ }^{34}$ Jutta Ciolek-Kümper, Wahlkampf in Lippe. Die Wahlkampfpropaganda der NSDAP zur Landtagswahl am 15. Januar 1933, München 1976, S.226-233. Vgl. den Beitrag von H.J.Priamus in diesem Band.

${ }^{35}$ Ebd., S. 242-245. Ähnliches stellt u. a. Rennspieß, Weltwirtschaftskrise, S.224, für Kamen fest; vgl. auch Anm. 32.

${ }^{36}$ Dies ist für Oldenburg (Schaap, Oldenburg, S. 178) und Hessen (Schön, Hessen, S. 196) belegt.

${ }^{37}$ Schaap, Oldenburg, S. 175; Ciolek-Kümper, Lippe, S. 97-99. - Der Einsatz des Hohenzollern-Prinzen August Wilhelm für die NSDAP ist bekannt. Auch das Waldeckische Fürstenhaus unterstützte sie offen. Siehe Günter Steiner, Waldecks Weg ins Dritte Reich. Gesellschaftliche und politische Strukturen eines ländlichen Raumes während der Weimarer Republik und zu Beginn des Dritten Reichs, Kassel 1990, S.17. Im Tätigkeitsbericht der NSDAP Gau Hessen-Nassau-Nord vom 6.1. 1931 wurde über eine Veranstaltung mit General Litzmann berichtet: „In Berfa, einem Ort von 700 Einwohnern, lauschten 1200 Schwälmer Bauern und Waldarbeiter, in die malerischen Trachten gekleidet, begeistert den Worten des greisen Heerführers." Archiv der Forschungsstelle für die Geschichte des Nationalsozialismus in Hamburg, Fasc. Nr.9114. In einem Bericht des zuständigen Landrats über einen SA-Aufmarsch am 3. August 1930 wurde ebenfalls vermerkt, daß sich eine Gruppe von „achtzig Schwälmer Bauern in Tracht und mit Parteiabzeichen“ dem Zug anschloß (Schön, Hessen, S.177).

${ }^{38}$ Schaap, Oldenburg, S. 145. 
deren Obhut Deutschlands Tor zur Welt gestellt ist? ${ }^{439}$ Kurz darauf hatte die Regierungskoalition bei der Bürgerschaftswahl am 27. September 1931 ihre Mehrheit verloren und die NSDAP mehr als ein Viertel der Wähler hinter sich vereinigt. Die Beschwörung regionalen Sonderbewußtseins nützte nichts mehr.

Zu den Parteien, deren Wähler 1930 in großer Zahl zur NSDAP übergingen, gehörten auch verschiedene Regionalparteien: die Deutsch-Hannoversche (Welfen-) Partei in Niedersachsen, die Landespartei (Schleswig-Holsteinische Bauern- und Landarbeiterdemokratie) in Schleswig-Holstein. Beide hatten sich zum Anwalt regionalen Sonderbewußtseins gegen Berlin gemacht, das als Synonym stand für die ungeliebte Weimarer Republik, für die vermeintliche politische Benachteiligung der Landwirtschaft, für Verstädterung und Modernisierung ${ }^{40}$. Nutznießer dieser umfassenden Negation alles Bestehenden wurde die NSDAP, die den radikalsten Willen zur Veränderung zeigte, dabei freilich für regionale Eigenentwicklung keinen Raum ließ. Konfessionelle und einzelstaatliche Sonderwünsche hätten zurückzustehen „hinter dem hohen Ziel eines einigen großdeutschen Vaterlandes", so hatten die hessischen Nationalsozialisten schon im Januar 1926 gegen die deutschvölkischen Konkurrenten postuliert ${ }^{41}$. So wie die NSDAP divergierende wirtschaftliche und soziale Interessen im grundsätzlichen Protest und Ruf nach Neuem zusammenfassen konnte, so überwand sie auch regionale Präferenzen.

Die fast widerstandslose Preisgabe der Länderrechte im Dritten Reich war damit vorgezeichnet. Die Gleichschaltung der Länder gelang Zug um Zug ohne Probleme. Ihre bisherigen politischen Repräsentanten waren nach dem schleichenden Schwund ihrer Handlungsmöglichkeiten in der Weltwirtschaftskrise demoralisiert und räumten sang- und klanglos das Feld. Der von vielen seit 1918 erstrebte zentralistische Einheitsstaat war erreicht, wenn auch in wesentlich anderer Form, als es sich die Hauptbefürworter, Sozialdemokraten und Demokraten, gedacht hatten. Für den Verlust an Macht und Eigenständigkeit entschädigten die Nationalsozialisten die Bayern, Rheinländer, Niedersachsen, Schlesier usw. nach erprobtem Muster durch symbolische Zugeständnisse an regionale Traditionen: das Schauspiel in der Potsdamer Garnisonskirche, die Berufung alteingesessener angesehener Persönlichkeiten in repräsentative, aber weitgehend einflußlose Ämter, die Pflege heimatlichen Brauchtums und Kulturguts in den "Gauen“ etc. Lange Zeit reichte das. Erst mit der generellen Distanzierung vom Nationalsozialismus seit 1943 entstand Raum für die Rückbesinnung auf eigene kulturelle Werte und geschichtliche Leistungen. So konnte regionales Selbstbewußtsein nach dem Zusammenbruch der zentralistisch organisierten Diktatur wieder politische Bedeutung und Wirkungskraft erlangen.

${ }^{39}$ Ursula Büttner u. Werner Jochmann, Hamburg auf dem Weg ins Dritte Reich, Entwicklungsjahre 1931-1933, Hamburg 1983, S. 81.

${ }^{40}$ Rietzler, Nordmark, S. 93-100; Noakes, Lower Saxony, S. 112-114.

${ }^{41}$ Schön, Hessen, S. 76. 